\title{
Lateralized Suppression of Alpha-Band EEG Activity As a Mechanism of Target Processing
}

\author{
Felix Bacigalupo ${ }^{1,2,3,4}$ and $@$ Steven J. Luck ${ }^{1}$ \\ ${ }^{1}$ Center for Mind and Brain, University of California, Davis, California 95616, ${ }^{2}$ Escuela de Psicología, Facultad de Ciencias Sociales, Pontificia Universidad \\ Católica de Chile, Santiago, Chile, ${ }^{3}$ Departamento de Psiquiatría, Facultad de Medicina, Pontificia Universidad Católica de Chile, Santiago, Chile, \\ and ${ }^{4}$ Centro Interdisciplinario de Neurociencia, Pontificia Universidad Católica de Chile, Santiago, Chile.
}

Alpha-band (8-12 Hz) EEG activity has been linked to visual attention since the earliest EEG studies. More recent studies using spatial cuing paradigms have shown that alpha is suppressed over the hemisphere contralateral to a to-be-attended location, suggesting that alpha serves as a mechanism of preparatory attention. Here, we demonstrate that alpha also plays a role in active target processing. EEG activity was recorded from a group of healthy male and female human subjects in two visual search experiments. In addition to alpha activity, we also assessed the N2pc event-related potential component, a lateralized transient EEG response that has been tightly linked with the focusing of attention on visual targets. We found that the visual search targets triggered both an N2pc component and a suppression of alpha-band activity that was greatest over the hemisphere contralateral to the target (which we call "target-elicited lateralized alpha suppression" or TELAS). In Experiment 1, both N2pc and TELAS were observed for targets presented in the lower visual field but were absent for upper-field targets. However, these two lateralized effects had different time courses and they responded differently to manipulations of crowding in Experiment 2. These results indicate that lateralized alpha-band activity is involved in active target processing and is not solely a preparatory mechanism and also that TELAS and N2pc reflect a related but separable neural mechanism of visuospatial attention.

Key words: alpha-band; attention; EEG; lateralization; N2pc

\section{Significance Statement}

The very first EEG studies demonstrated that alpha-band $(8-12 \mathrm{~Hz})$ EEG oscillations are suppressed when people attend to visual information and more recent research has shown that cuing an individual to expect a target at a specific location produces lateralized suppression in the contralateral hemisphere. Therefore, lateralized alpha may serve as a preparatory mechanism. In the present study, we found that a similar lateralized alpha effect is triggered by the appearance of a visual target even though the location could not be anticipated, demonstrating that alpha also serves as an active mechanism of target processing. Moreover, we found that alpha lateralization can be dissociated from other lateralized measures of target selection, indicating that it reflects a distinct mechanism of attention.

\section{Introduction}

Alpha-band (8-12 Hz) EEG oscillations have been linked to visual processing and attention since the invention of EEG and the early recordings performed by Berger (1929) and Adrian and Matthews (1934). These early studies found that alpha power decreases tonically when the eyes are open compared with when

Received Jan. 22, 2018; revised 0ct. 25, 2018; accepted Nov. 30, 2018

Author contributions: F.B. and S.J.L. wrote the first draft of the paper; F.B. and S.J.L. edited the paper; F.B. and S.J.L. designed research; F.B. performed research; F.B. analyzed data; F.B. and S.J.L. wrote the paper.

This work was supported by the National Institutes of Health (Grant R01MH076226 to S.J.L.) and Becas-Chile CONICYT (scholarship to F.B.). We thank Dr. Tomas Ossandon for comments.

The authors declare no competing financial interests.

Correspondence should be addressed to Felix Bacigalupo at fobaciga@uc.cl.

https://doi.org/10.1523/JNEUROSCI.0183-18.2018

Copyright $\odot 2019$ the authors $\quad 0270-6474 / 19 / 390900-18 \$ 15.00 / 0$ they are closed and subsequent research showed that alpha power also decreases phasically when a task-relevant visual stimulus appears or when visual attention is engaged (Pollen and Trachtenberg, 1972; Ray and Cole, 1985; Hanslmayr et al., 2011). This link between alpha suppression and attention may reflect the fact that decreased alpha power is associated with increased cortical excitability (Klimesch, 2012).

A classic study by Worden et al. (2000) found that alpha suppression is lateralized with respect to an attended location and this result has been replicated and extended by many following studies (Worden et al., 2000; Rihs et al., 2007; Jensen and Mazaheri, 2010; Doesburg et al., 2016). These studies used spatial cuing paradigms and found that the cue elicits a reduction in alpha power over both hemispheres, but with a greater reduction over the hemisphere contralateral to the cued location. These effects 
a

Experiment 1 Stimuli
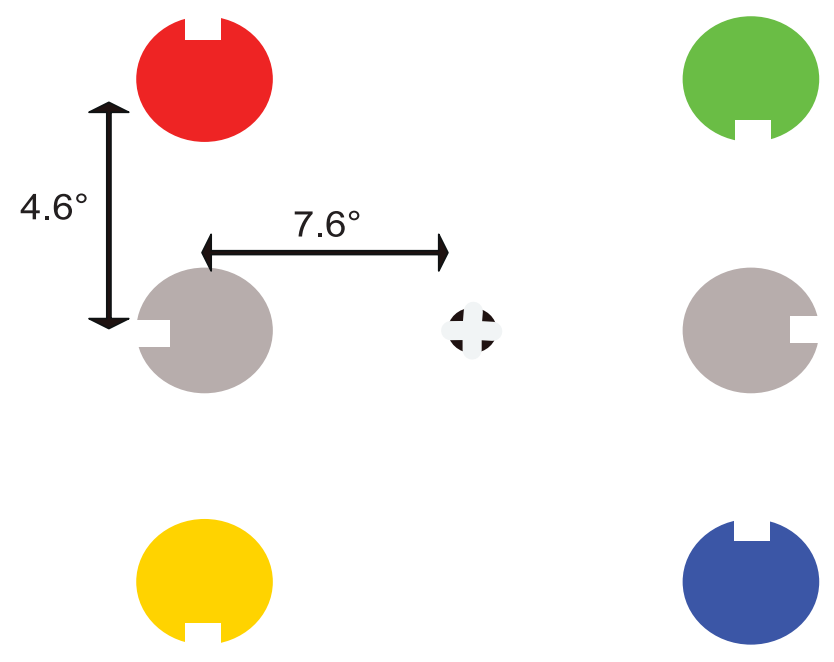

b

\section{Experiment 2 Stimuli}
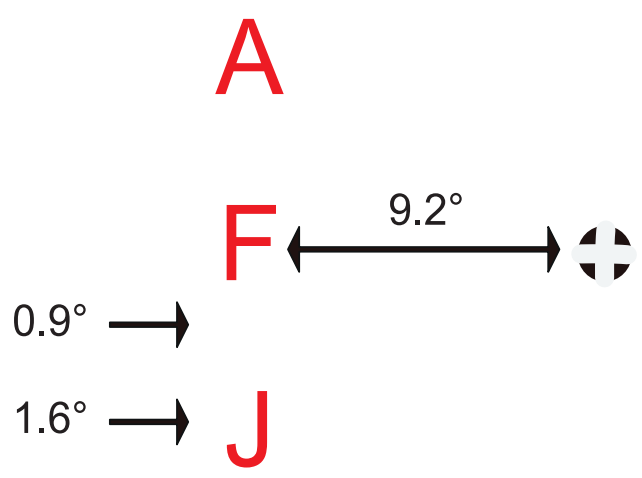

Figure 1. Example stimuli from the two experiments. $\boldsymbol{a}$, Experiment 1 task. One color was designated the target color at the beginning of each block and participants were instructed to report whether the target-colored circle had a gap on the top or on the bottom. Target location varied unpredictably from trial to trial. $\boldsymbol{b}$, Experiment 2 task. One color was designated as the target color at the beginning of each block. Participants were instructed to report whether the middle letter in the set of letters of this color was a vowel or a consonant. The middle letter was always on the horizontal meridian and the flankers could be absent, $1.6^{\circ}$ above and below the middle letter, or $0.9^{\circ}$ above and below the middle letter. The side containing the target color varied unpredictably from trial to trial.

have led to the view that lateralized changes in alpha-band power reflect a mechanism of preparatory visuospatial attention that improves the processing of subsequent targets and/or suppresses the processing of subsequent distractors.

However, there are two reasons to suspect that lateralized alpha-band EEG suppression may not solely reflect preparatory activity and may also reflect active processing of target information. First, alpha power over both hemispheres is suppressed in response to foveal targets (Payne et al., 2013), presumably reflecting active processing of the target, and a lateralization of this effect for peripheral targets might be expected as a result of the contralateral organization of the visual system. Second, van Diepen et al. (2016) used a spatial cuing paradigm and found that both the cue and the target elicited lateralized alpha effects (van Diepen et al., 2016).

The present study was designed to determine whether targets elicit lateralized alpha suppression in visual search paradigms in suppression. the absence of spatial precues, which would indicate that this effect can reflect active target processing and is not limited to preparatory processing. In addition, we sought to determine whether this effect represents a unique mechanism of attention that can be dissociated from other lateralized electrophysiological signatures of attention. Specifically, we compared the target-elicited lateralized alpha suppression (TELAS) with the N2pc component of the event-related potential (ERP) waveform. The N2pc component is a well characterized and well validated measure of the allocation of attention to lateralized target stimuli (Luck, 2012; Eimer, 2015). It typically appears as a negative voltage deflection from $\sim 150$ $300 \mathrm{~ms}$ over the hemisphere contralateral to an attended object within a bilateral stimulus array (Luck and Hillyard, 1994), is mainly generated in ventral stream visual areas (Hopf et al., 2006), and is sensitive to the same experimental manipulations as single-unit activity in macaque homologs of these areas (Luck et al., 1997).

To determine whether target-elicited lateralized alpha suppression reflects the same attentional mechanism as the N2pc component, we investigated whether these two effects are influenced in the same manner by two experimental manipulations that are known to modulate $\mathrm{N} 2 \mathrm{pc}$ amplitude: the vertical position of the target (Luck et al., 1997) and the distance between the target and the distractors (Bacigalupo and Luck, 2015). If target-elicited lateralized alpha suppression can be experimentally dissociated from the N2pc component, then this would indicate that they represent different attentional mechanisms and presumably play different roles in target processing and/or distractor suppression.

\section{Materials and Methods}

Methods overview. To evaluate whether alpha lateralization effects play a role in active target processing, we conducted two simplified visual search experiments in which a target and simultaneous distractors were presented without spatial precues (Fig. 1). We expected to find that the lateralized targets would elicit greater suppression of alpha-band EEG activity over the contralateral hemisphere than over the ipsilateral hemisphere. To test whether target-elicited lateralized alpha suppression is a separate attentional marker from the N2pc, both signals were measured and evaluated from the same raw EEG signals on the same trials. In Experiment 1 (Fig. 1a), the vertical position of the target, which is known to modulate N2pc amplitude, was manipulated. In particular, the N2pc is much larger for targets in the lower visual field (VF) than for upper VF targets (Luck et al., 1997) and our goal was to determine whether the same pattern would be observed for target-elicited lateralized alpha

To further evaluate whether target-elicited lateralized alpha suppression and the N2pc are dissociable, Experiment 2 used a crowding para- 


\section{a Experiment 1 Horizontal electro-oculogram (HEOG)}

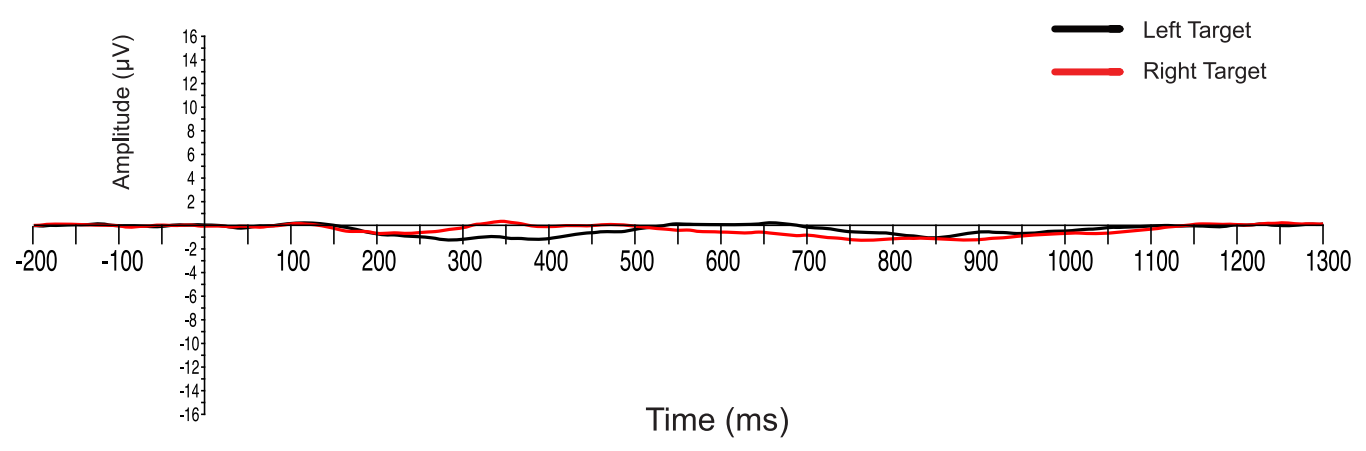

\section{b Experiment 2 Horizontal electro-oculogram (HEOG)}

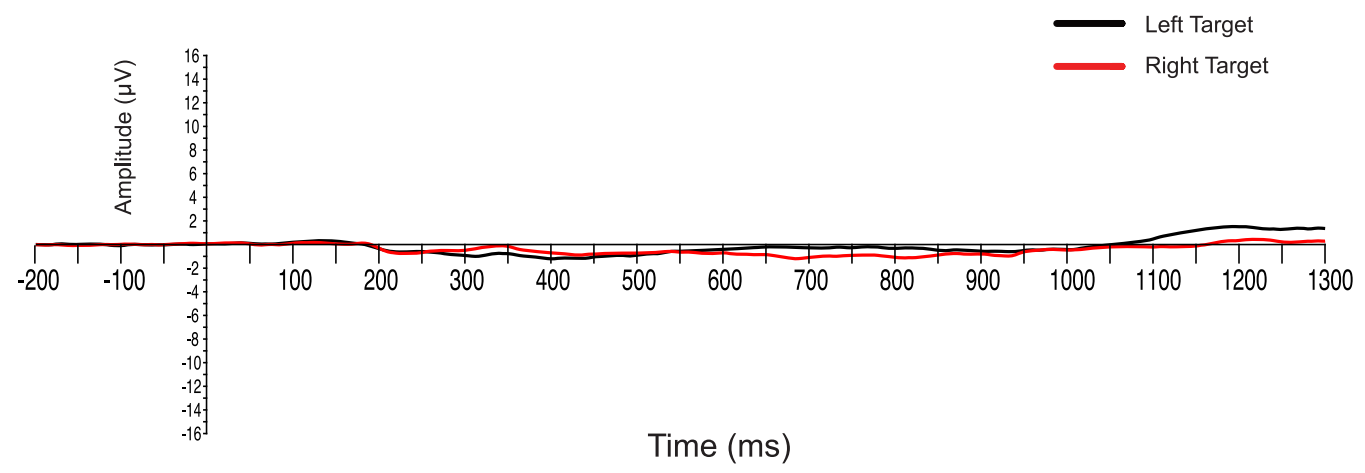

Figure 2. HEOG waveforms (after artifact rejection) for left-side and right-side targets in Experiments 1 ( $\boldsymbol{a})$ and $2(\boldsymbol{b})$. The scale of $\pm 16 \mu \mathrm{V}$ reflects a horizontal eye deviation of $\pm 1^{\circ}$. Therefore, on average, the residual eye movements were negligible $\left(<0.1^{\circ}\right)$.

digm in which target-distractor distance was manipulated (Fig. 1b). Previous research has shown that N2pc amplitude is greater at intermediate target-flanker distances compared with both no-flankers and densely crowded conditions (Bacigalupo and Luck, 2015). An unpublished exploratory analysis of the data published in this prior study yielded evidence of the existence of target-elicited lateralized alpha suppression and also suggested that the effects of crowding differed between this effect and the N2pc component. However, the timing parameters used in that study were not ideal for examining alpha-band activity and the observed effects relied on post hoc analyses. The present study was therefore conducted to provide more optimal task parameters using an $a$ priori analysis framework (derived from the post hoc analyses of the previous study), which increases the strength of the conclusions that can be drawn.

Participants. A single group of 22 healthy University of California (UC) Davis students (17 females) with no history of neurological or psychiatric conditions participated in both experiments in a single session after providing informed consent. Their ages ranged from 18 to 25 years, with a mean of 20.7 years. This study was approved by the UC Davis Institutional Review Board.

As described in more detail below, we always exclude participants for whom $>25 \%$ of trials are rejected because of artifacts (Luck, 2014). One participant exceeded this threshold in both experiments and this individual was excluded from all analyses.

Experiment 1 stimuli and task. The stimuli used in Experiment 1 are illustrated in Figure 1a. The participants were seated $100 \mathrm{~cm}$ from an LCD monitor with a black background and a $60 \mathrm{~Hz}$ refresh rate. An empirically optimal fixation cross drawn in black and subtending $0.65^{\circ}$ was continuously visible in the center of the display (Thaler et al., 2013).
A photodiode was used to measure the delay of the monitor at each stimulus location. Before all signal processing and analyses, the stimulus event codes were shifted to reflect the true stimulus onset time at the location of the target.

The stimuli consisted of two columns of three vertically arranged circles $\left(1.3^{\circ}\right.$ diameter $)$ centered $7.6^{\circ}$ to the left and right sides of the vertical midline (Fig. 1a). The center-to-center distance between the middle circles and the top and bottom circles in each column was $4.6^{\circ}$. Stimulus luminance was $32 \mathrm{~cd} / \mathrm{m}^{2}$. The middle circle in each column was gray and had a $0.4^{\circ}$ square gap either on the left or right side. The upper and lower circles in each array were selected at random without replacement on each trial from the colors blue, green, red, or yellow and had a $0.4^{\circ}$ square gap either on the top or bottom. The middle circles were never targets and were included to provide competing nearby stimuli for the top and bottom circles, which maximizes N2pc amplitude (Luck et al., 1997; Bacigalupo and Luck, 2015).

The task was divided into eight blocks - two per target color-and each block consisted of 72 trials. The target color was specified at the beginning of each block and participants were instructed to report whether the target-colored circle had a gap on top or bottom by pressing one of two buttons on a game pad with the dominant hand (index finger for upper gap; middle finger for lower gap). The stimulus duration was $200 \mathrm{~ms}$ and the stimulus onset asynchrony (SOA) varied randomly between 3000 and $3300 \mathrm{~ms}$. Note that this SOA was longer than is typical for an N2pc experiment, which is helpful for performing time-frequency (TF) analyses.

Experiment 2 stimuli and task. For Experiment 2, the stimuli consisted of two arrays of three vertically oriented letters in Times New Roman typeface (Fig. $1 b$ ). Each letter subtended $0.8^{\circ}$ vertically and was centered $9.2^{\circ}$ to the left or right of the vertical meridian. Stimulus luminance was 


\section{Experiment 1 Behavioral Results}

a Correct Response Rate (\%)

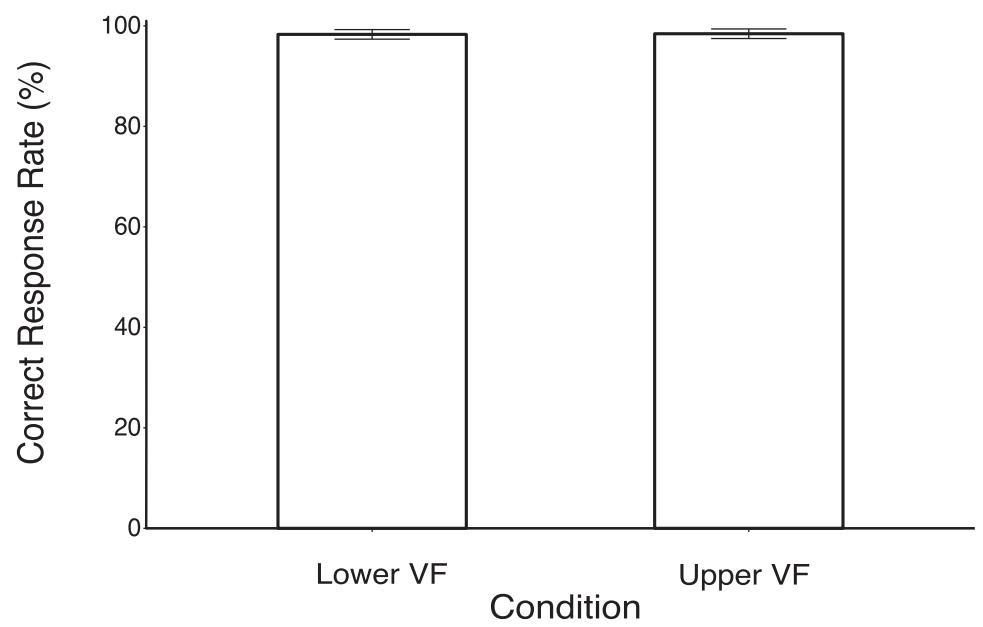

b

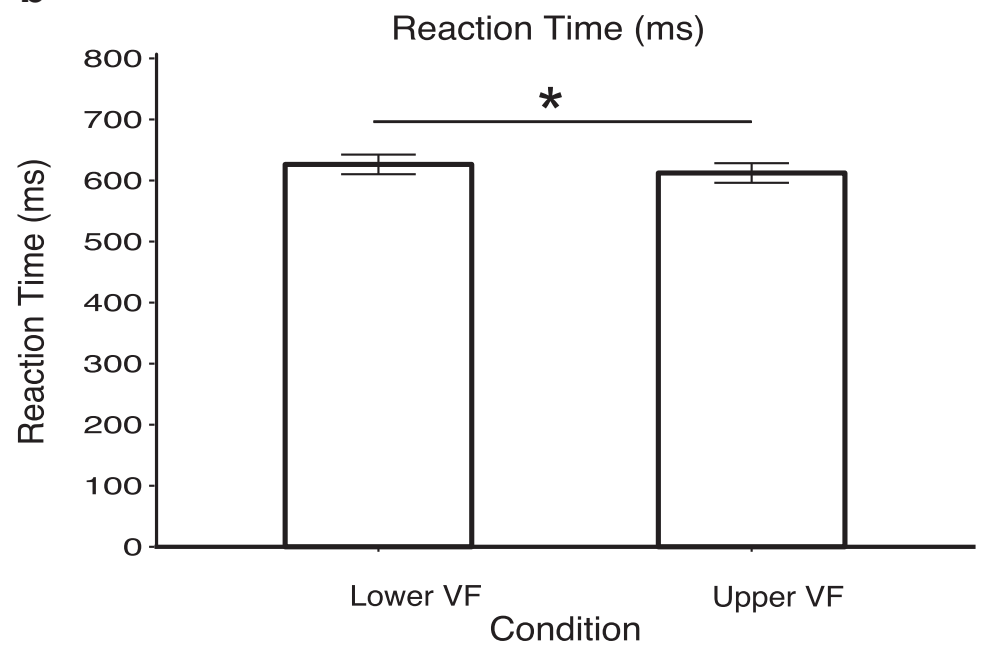

Figure 3. Mean correct response rate $(\boldsymbol{a})$ and mean $\mathrm{RT}(\boldsymbol{b})$ for Experiment $1 .{ }^{*} p<0.05$. Error bars indicate the within-subjects SEM.

$32 \mathrm{~cd} / \mathrm{m}^{2}$. The letters on one side were red and the letters on the other side were green (varied unpredictably across trials). Each letter was randomly selected without replacement on each trial from a group of five vowels (A, E, I, O, U) and five consonants (N, F, L, G, J).

The session was divided into eight blocks of 72 trials. One color was designated as the attended color at the beginning of each block. Participants were instructed to report whether the middle letter in the set of letters of this color was a vowel or a consonant by pressing one of two buttons on a gamepad. The target color changed on every block. The middle letter was always on the horizontal meridian, and there were three levels of crowding between this letter and the other letters (the flankers): (1) no flankers, (2) flanker letters centered $1.6^{\circ}$ above and below the middle letter, and (3) flanker letters centered $0.9^{\circ}$ above and below the middle letter.

Electrophysiological recordings. The EEG was recorded using a Brain Products actiCHamp system with electrodes located over the left and right mastoid processes and at 27 standard scalp locations (FP1, FP2, F3, F4, F7, F8, C3, C4, P3, P4, P5, P6, P7, P8, P9, P10, PO3, PO4, PO7, PO8, $\mathrm{O} 1, \mathrm{O} 2, \mathrm{Fz}, \mathrm{Cz}, \mathrm{Pz}, \mathrm{POz}$, and $\mathrm{Oz}$ ). The horizontal and vertical EOG signals were measured from electrodes located $\sim 1 \mathrm{~cm}$ lateral to the outer canthi of each eye and from an electrode placed below the right eye.

All signals were recorded in single-ended mode and digitized at 1000
$\mathrm{Hz}$ after application of a cascaded integratorcomb antialiasing filter with a half-power cutoff at $260 \mathrm{~Hz}$. Electrode impedances were kept below $80 \mathrm{~K} \Omega$. After acquisition, all data analyses were performed in MATLAB using EEGLAB Toolbox (Delorme and Makeig, 2004), ERPLAB Toolbox (Lopez-Calderon and Luck, 2014), and FieldTrip (Oostenveld et al., 2011). The signals were resampled offline to $250 \mathrm{~Hz}$, referenced to the average of the two mastoid electrodes, and high-pass filtered using a noncausal Butterworth filter (half-amplitude cutoff $=0.1 \mathrm{~Hz}$, slope $=12 \mathrm{~dB}$ /octave).

Before artifact correction, the horizontal EOG (HEOG) was computed as the difference between the electrodes lateral to each eye and the vertical EOG (VEOG) was computed as the difference between the electrode below the right eye and the Fp2 electrode. To correct for eye blinks and horizontal eye movements, independent component analysis (ICA) was applied using EEGLAB's BINICA routine using all electrodes except for the mastoid electrodes and the previously computed HEOG and VEOG channels. The criterion for excluding an ICA component was the consistency between the shape, timing, and spatial location of the component compared with the HEOG and VEOG signals. For eye blinks, one or two components were identified per subject; for horizontal eye movements, one component was identified in each participant. The data for each channel (excluding the HEOG and VEOG channels) were then reconstructed from the other ICA components. By maintaining the uncorrected HEOG and VEOG channels, it was possible to reject individual trials in which blinks or eye movements occurred during a time period in which they might have changed the sensory input (Luck, 2014).

Individual trials were rejected if the behavioral response was incorrect, if the peak-topeak voltage was $>200 \mu \mathrm{V}$ in any $200 \mathrm{~ms}$ window in any electrode, or if a blink or eye movement (defined as a step-like voltage change; see Luck, 2014) was detected in the uncorrected HEOG signal between 100 and 600 ms poststimulus or in the VEOG signal between $200 \mathrm{~ms}$ prestimulus and $400 \mathrm{~ms}$ poststimulus. The average residual eye movements in the uncorrected HEOG signal were $<3.2 \mu \mathrm{V}$ for all conditions, which corresponds to an eye rotation of less than $\pm 0.1^{\circ}$ with an estimated voltage propagation of $<0.1 \mu \mathrm{V}$ at the posterior scalp sites (Lins et al., 1993). Figure 2 shows HEOG waveforms (after artifact rejection) for left-side and right-side targets in each experiment, demonstrating that any residual eye movements were negligible.

More than 25\% of trials were rejected because of artifacts in one participant and this participant was therefore excluded from the analyses of both experiments. For the 21 remaining participants, the average percentage of rejected trials was $9.3 \%$ (range $=0.7-25 \%$ ) in Experiment 1 and $6.4 \%$ (range $=0.2-21.9 \%$ ) in Experiment 2. Identical EEG data epochs were used for the N2pc and alpha analyses.

ERP analyses. Averaged ERP waveforms were computed with a 3000 ms epoch starting $1500 \mathrm{~ms}$ before and ending $1500 \mathrm{~ms}$ after stimulus onset. The ERP measurements were performed using a $200 \mathrm{~ms}$ prestimulus baseline. A low-pass filter (half-amplitude cutoff $=30 \mathrm{~Hz}$, slope $=12 \mathrm{~dB}$ /octave) was applied after averaging for plotting purposes.

The N2pc ERP component was computed as the average amplitude from contralateral-minus-ipsilateral difference waves relative to the side 
a Upper Visual Field Target

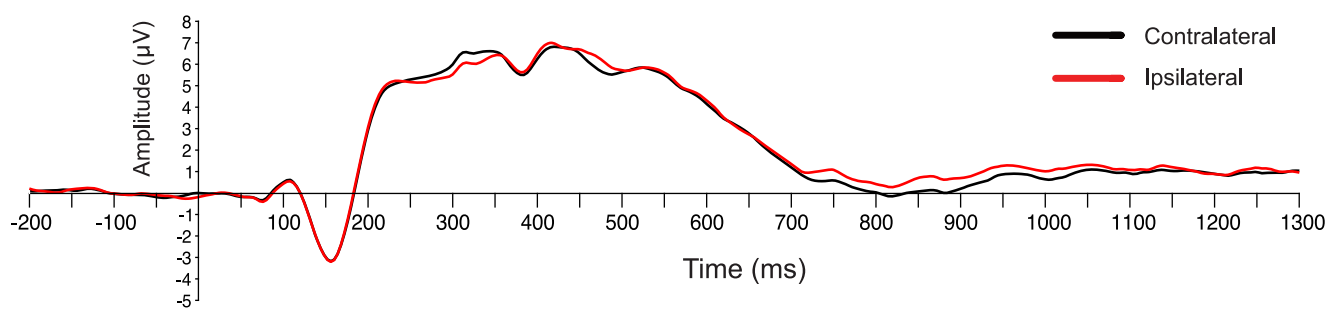

\section{b Lower Visual Field Target}

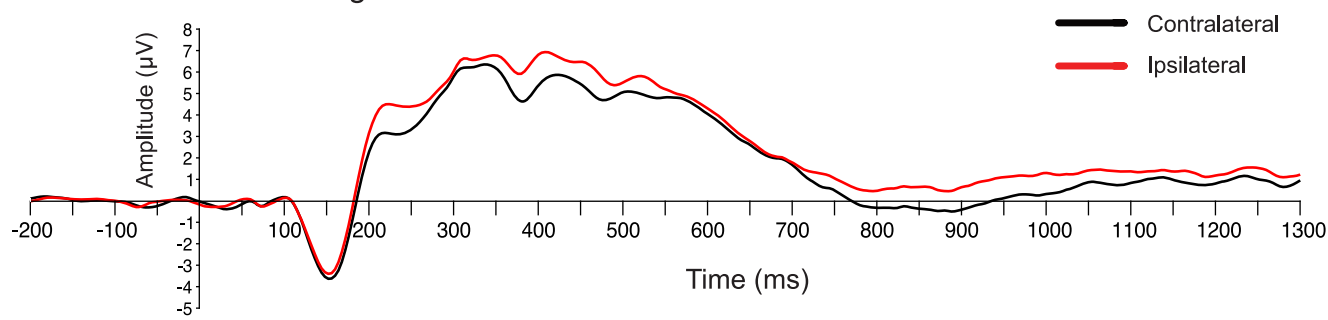

C Difference waves
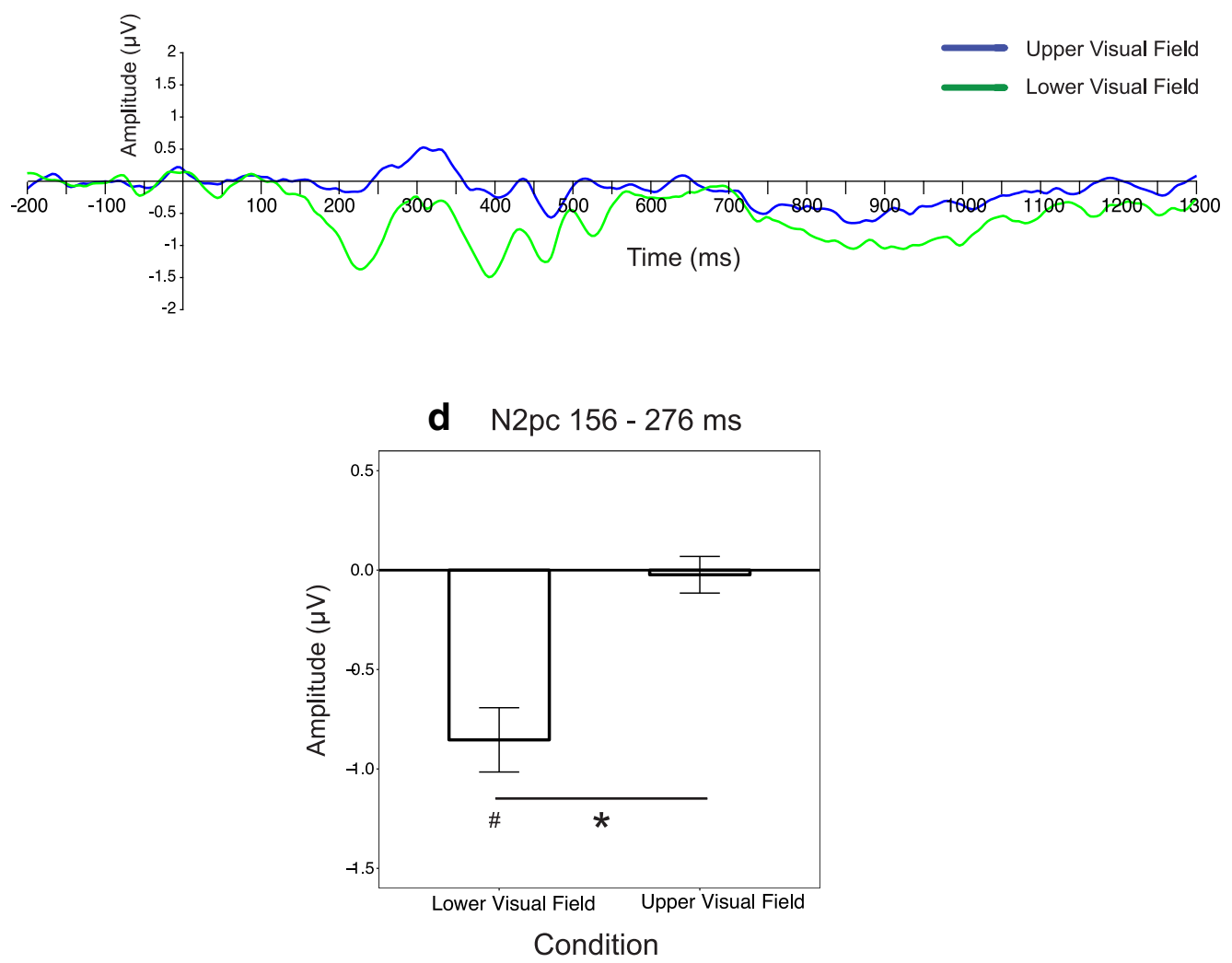

Figure 4. Grand average ERPs from Experiment 1. Contralateral and ipsilateral ERP waveforms are shown for targets in the upper VF (a) and lower VF (b). $\boldsymbol{c}$, Contralateral-minus-ipsilateral difference waves. $\boldsymbol{d}$, Mean N2p c amplitude measured from the difference waves. Error bars indicate the within-subjects SEM. $\# p<0.05$ for difference from zero. ${ }^{*} p<0.05$ for comparison of upper and lower VFs.

of the target at the PO3 and PO4 electrode sites. These sites were chosen a priori on the basis of our previous crowding study (Bacigalupo and Luck, 2015). To avoid biases in selecting the time period for analysis, we used the "collapsed localizer" approach to determine the measurement window (Luck and Gaspelin, 2017). Specifically, we computed a contralateral-minus-ipsilateral difference wave that was averaged across all experimental conditions and all participants and the measurement window was defined as the onset and offset of the N2pc in this averaged difference wave (the latencies at which the voltage reached 15\% of the peak amplitude). This procedure resulted in a measurement window of 156-276 ms in Experiment 1 and 132-252 ms in Experiment 2. Mean N2pc amplitude was then measured in these time windows for each individual condition in the single-participant difference waveforms.

TF analyses. TF analyses were performed on the same $3000 \mathrm{~ms}$ EEG epochs used for the ERP analyses. The frequency representation of the EEG data was obtained through convolution in the time domain using Morlet wavelets from $2-30 \mathrm{~Hz}$ (in steps of $1 \mathrm{~Hz}$ ) and a Gaussian taper, with analysis windows centered every $50 \mathrm{~ms}$ (Spaak et al., 2014). Because our main goal was to compare the N2pc component with alpha-band 


\section{Experiment 1 N2pc Topographic Plots (156 - 276 ms)}

\section{a Upper VF}

Left Target

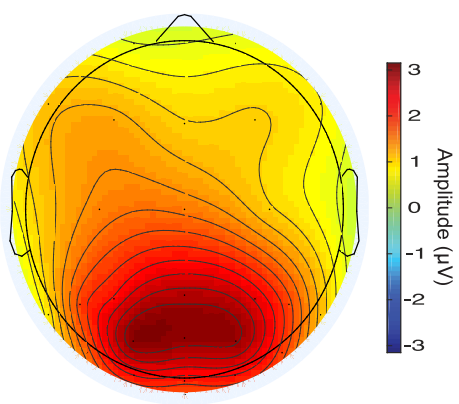

b Lower VF
Right Target

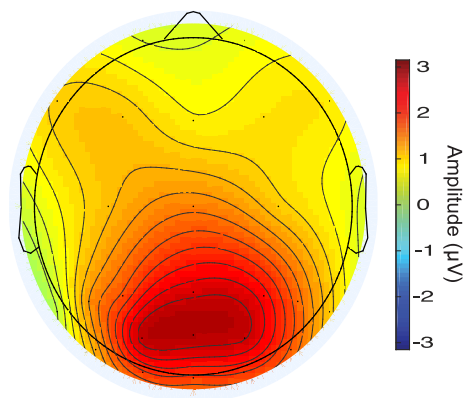

Contra - Ipsi Difference

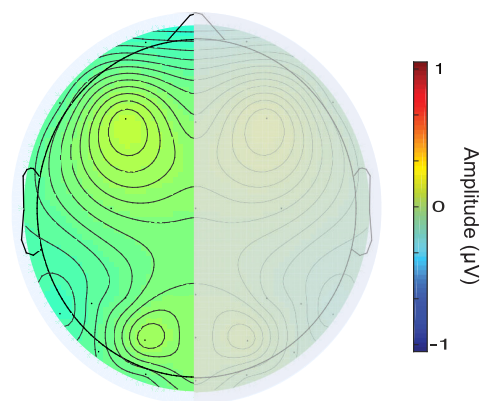

Contra - Ipsi Difference

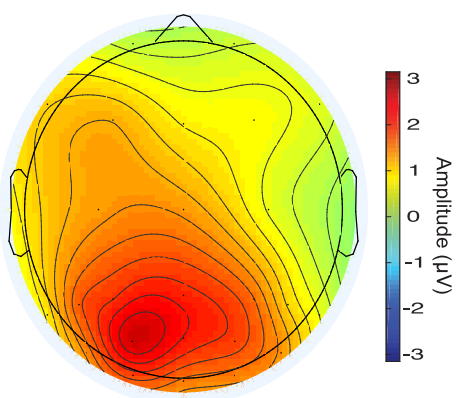

Right Target

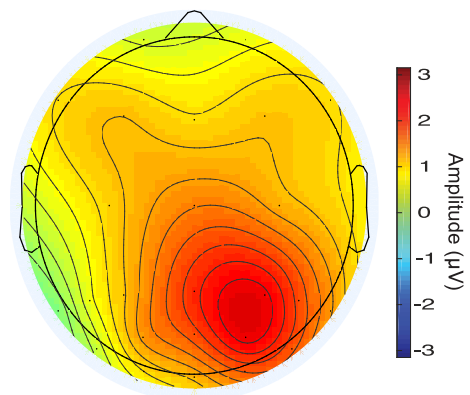

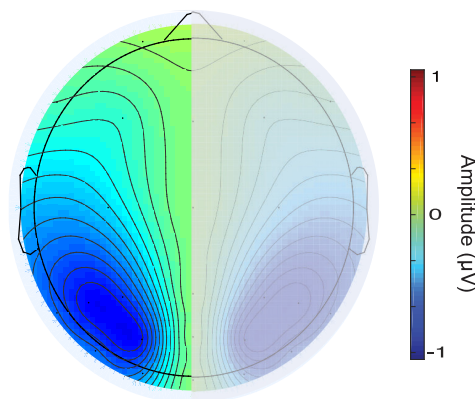

Figure 5. Topographic plots of the averaged ERP during the N2pc window for left and right targets and for the contralateral-minus-ipsilateral difference for upper VF ( $\boldsymbol{a})$ and lower VF $(\boldsymbol{b})$ targets. Given the way the data are combined to derive the N2pc component, the left and right hemispheres are necessarily mirror images. The typical occipitotemporal N2pcscalp distribution was observed for the lower VF ( $\boldsymbol{b}$, right), but little or no contralaterality was observed for the upper VF target condition ( $\boldsymbol{a}$, right).

suppression, temporal resolution was more important than frequency resolution, so we used three-cycle wavelets (as in van Diepen et al., 2016). At $10 \mathrm{~Hz}$, the temporal precision was $48 \mathrm{~ms}$ and the frequency precision was $3.3 \mathrm{~Hz}$ (quantified as the SD in time or frequency). To compute induced power, the averaged ERP waveform was subtracted from the single-trial EEG signals for each experimental condition. The TF transform was then computed from the single-trial signals and the transformed data were averaged across trials for each specific time point and frequency.

After induced power (IP) was calculated, the data were normalized according to a decibel scale using the following equation (modified from Grandchamp and Delorme, 2011):

$$
I P_{\log }(f, t)=10 \log _{10}\left(I P_{\%}(f, t)\right)
$$

where $I P_{\%}(f, t)=\frac{I P(f, t)}{\mu B(f)}$ and $\mu B(f)$ is the mean spectral estimate for all baseline points at frequency $f$ using a prestimulus baseline period starting $300 \mathrm{~ms}$ before stimulus onset (Grandchamp and Delorme, 2011). We used a slightly longer baseline for the TF analysis than for the ERP analysis to account for the width of the
Morlet wavelet at $10 \mathrm{~Hz}(\sim 300 \mathrm{~ms})$. Alpha-band power was computed by averaging the power across an $a$ priori frequency band of 8-12 Hz. Lateralized alpha-band power was calculated by subtracting the ipsilateral power from the contralateral power (relative to the side of the target) at the PO3 and PO4 electrode sites. These sites were chosen a priori to match the sites used for the $\mathrm{N} 2 \mathrm{pc}$ analyses, but they were also the lateralized sites with greatest alpha suppression effects (see Figs. 6, 7, 8, 12, 13, 14).

To compare the N2pc with the alpha-band activity across the different experimental conditions, the time window used for measuring the $\mathrm{N} 2 \mathrm{pc}$ amplitude was also used for measuring alpha-band power (156-276 ms and 132-252 ms after stimulus onset for Experiments 1 and 2, respectively). However, to further characterize the timing of the alpha-band effects, additional analyses were also conducted using the mean alpha-band power from three additional time windows (selected on the basis of a preliminary analysis of the similar study of Bacigalupo and Luck, 2015): 
a Upper Visual Field Target
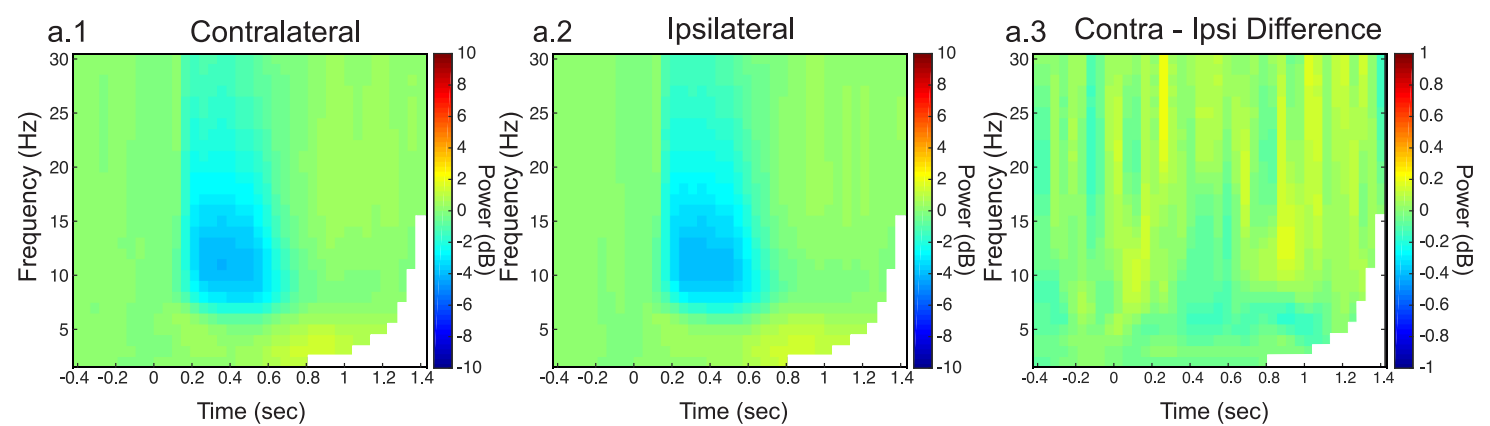

\section{b Lower Visual Field Target}
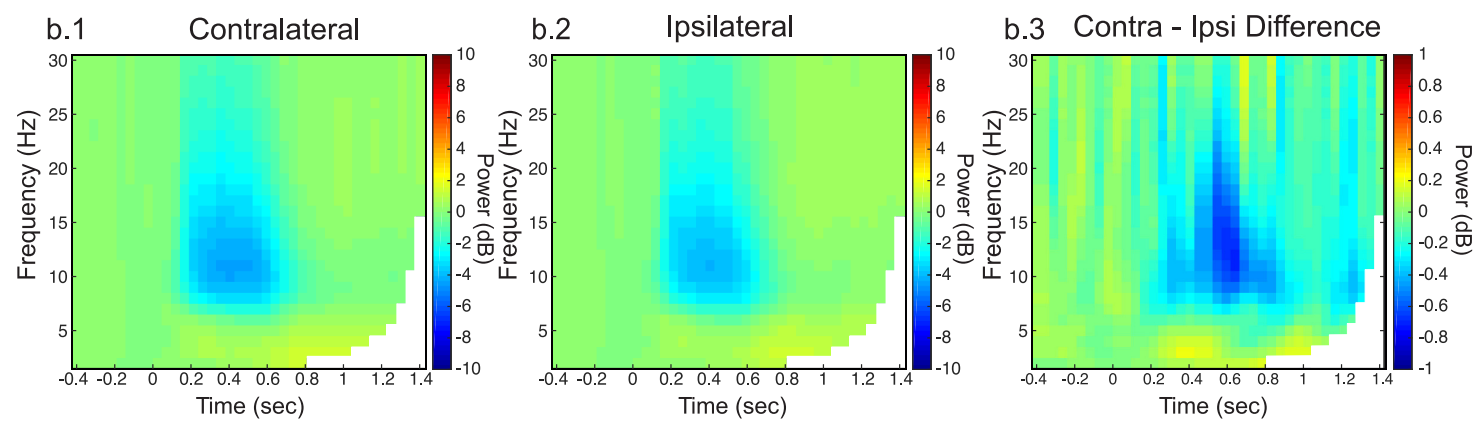

\section{c Alpha (8-12 Hz) Power (dB), Contra - Ipsi Difference}

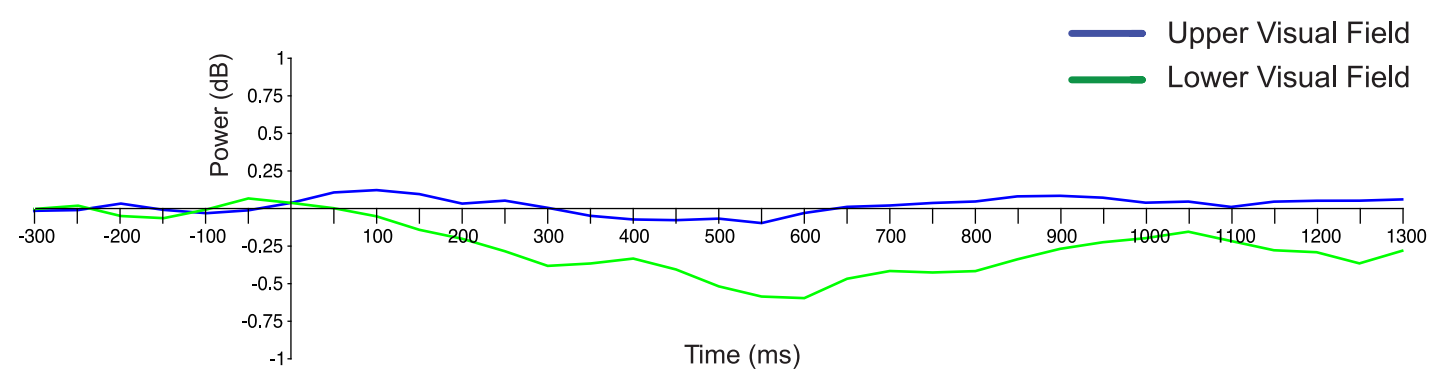

Figure 6. Grand average TF plots from Experiment 1. $\boldsymbol{a}$, Upper VF targets that elicited approximately equivalent suppression of alpha-band power for both contralateral and ipsilateral electrodes relative to the target location $(\boldsymbol{a} . \mathbf{3}) \cdot \boldsymbol{b}$, Lower-field targets, which elicited greater alpha-band suppression over the contralateral hemisphere $(\boldsymbol{b} .3)$. The white region at the bottom right corner of the plots indicates values that are undefined given the epoch length and wavelet duration. $c$, Time course of the contralateral-minus-ipsilateral difference in alpha-band power.

(1) early (200-600 ms), (2) middle (600-900 ms), and (3) late (900-1200 ms).

Statistical analyses. Paired $t$ tests and repeated-measures ANOVAs (alpha $=0.05$ ) were computed using R statistical software version 3.3.0. (R Development Core Team, 2013). Onesample $t$ tests were used when N2pc amplitude or lateralized alpha power from a single condition was being compared with zero. The Pearson $r$ correlation coefficient was used to assess the association between alpha, the N2pc, and behavioral [reaction time (RT) and correct response rate] measurements.

\section{Results}

\section{Experiment 1 behavior}

As shown in Figure $3 a$, accuracy in Experiment 1 was near ceiling (98\%) and did not differ between upper VF and lower VF targets $\left(t_{(20)}=0.6, p=0.55\right)$. RTs were slightly but significantly faster for upper VF targets ( mean $=612, \mathrm{SEM}=16.6 \mathrm{~ms}$ ) than for lower VF targets $\left(\right.$ mean $=626, \mathrm{SEM}=18 \mathrm{~ms} ; t_{(20)}=3.9, p<0.001$; Fig. $3 b$ ). Previous studies have also reported faster RTs for visual search targets located in the upper VF (Previc and Blume, 1993; Gunter et al., 1994). According to Previc (1990), this upper VF attentional facilitation may reflect the extrapersonal system of visual attention that is involved in visual search and depends on the integrity of the inferior temporal cortex. In contrast, the peripersonal system of visual attention is biased toward the lower VF is involved in reaching and visuomotor activities and is disrupted by parietal cortex lesions (Previc, 1990).

\section{Experiment 1 ERPs}

As shown in Figure 4, the ERP waveform was more negative (less positive) over the hemisphere contralateral to the target than the hemisphere ipsilateral to the target during the N2pc measurement window (156-276 ms) for lower VF targets. However, this effect was largely absent for upper VF targets. The N2pc was isolated from the rest of the ERP waveform by means of contralateral-minus-ipsilateral difference waves (Fig. 4c), which show a clear negative deflection peaking at $\sim 225 \mathrm{~ms}$ for the lower VF target. As is commonly observed, the N2pc declined in ampli- 


\section{Experiment 1 Alpha Topographic Plots (156 - 276 ms)}

\section{a Upper VF}

\section{Left Target}

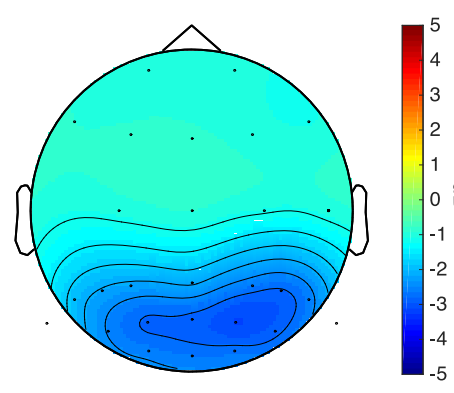

b Lower VF
Right Target

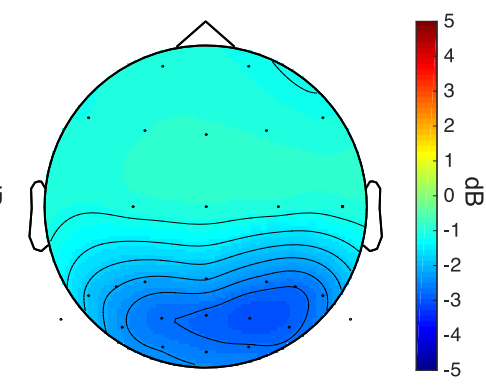

\section{Contra - Ipsi Difference}

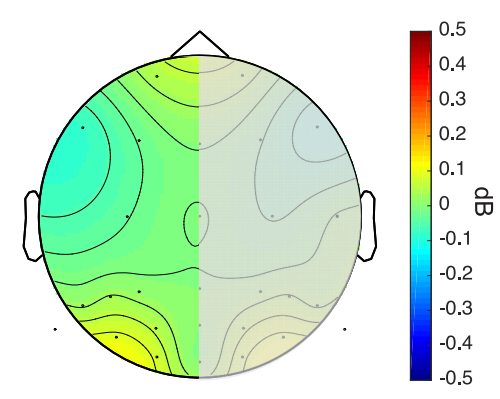

Contra - Ipsi Difference

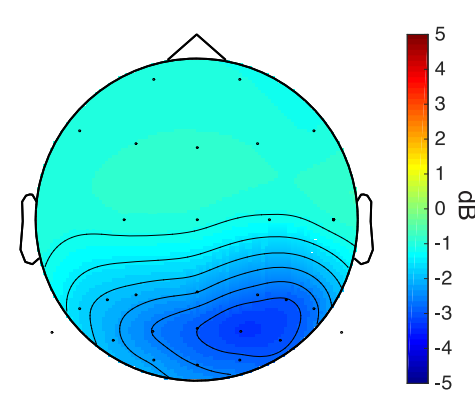

Right Target

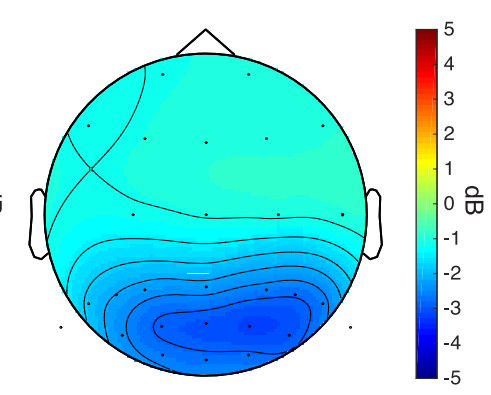

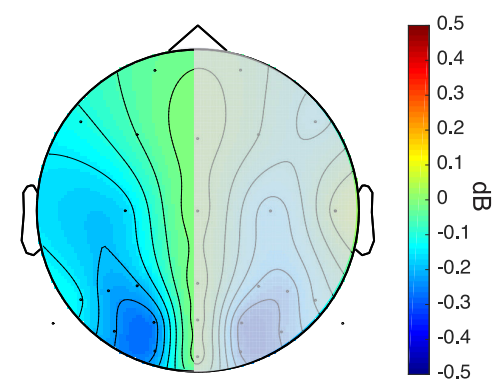

Figure 7. Topographic plots of induced alpha band ( $8-12 \mathrm{~Hz}$ ) activity during the N2pc time window for left and right targets and for the contralateral-minus-ipsilateral difference for upper VF $(\boldsymbol{a})$ and lower VF $(\boldsymbol{b})$ targets. A lateralization effect was observed for lower VF targets ( $\boldsymbol{b}$, right), but not for upper VF targets ( $\boldsymbol{a}$, right).

tude from $\sim 250-350 \mathrm{~ms}$ and this was followed by a sustained negativity (the sustained posterior contralateral negativity or SPCN) (Maheux and Jolicour, 2017). Another negativity was also present very late from $\sim 700-1200 \mathrm{~ms}$.

By contrast, upper VF targets elicited very little contralateral negativity but did elicit a contralateral positivity from $\sim 250-350$ $\mathrm{ms}$. This positivity may reflect the distractor positivity $\left(\mathrm{P}_{\mathrm{D}}\right)$ component that often follows N2pc (Sawaki et al., 2012), which would suggest that $\mathrm{P}_{\mathrm{D}}$ and $\mathrm{N} 2 \mathrm{pc}$ are differentially sensitive to the vertical position of the relevant stimulus. The pattern of $\mathrm{N} 2 \mathrm{pc}$ differences between upper and lower VF targets is quite similar to what has been observed previously (Luck et al., 1997). The topographic distribution of the ERP during the N2pc time window is shown in Figure 5, in which lateralization effects can be seen for lower VF but not for upper VF targets.

To provide statistical support for the observed N2pc effects, we conducted a priori statistical tests on the mean voltage from 156-276 ms in the contralateral-minus-ipsilateral difference waves. N2pc amplitude was significantly greater for lower VF targets than for upper VF targets $\left(t_{(20)}=4.42, p<0.001\right)$. In addition, N2pc amplitude was significantly greater than zero for lower VF targets $\left(t_{(20)}=-5.28, p<0.001\right)$, but not for upper VF targets $\left(t_{(20)}=-0.25, p=0.8\right)$.

\section{Experiment $1 \mathrm{TF}$ analysis}

Figure 6 provides TF plots along with waveforms showing the time course of activity averaged across the alpha-band frequency range $(8-12 \mathrm{~Hz})$. As commonly observed, alpha-band power was suppressed (relative to the pre-stimulus level) from $\sim 200-600$ $\mathrm{ms}$ after the appearance of the target. This suppression was observed over both contralateral and ipsilateral scalp sites for both upper VF and lower VF targets, and Figures 7 and 8 show that this effect had an occipitotemporal topographic scalp distribution. The suppression effect was distributed over a wide band of frequencies $(\sim 7-20 \mathrm{~Hz})$, but this may reflect the relatively poor frequency resolution of the 3-cycle wavelet that we used to optimize the temporal resolution of the analyses. However, the effect was clearly strongest in the alpha band $(8-12 \mathrm{~Hz})$.

Although strong alpha-band suppression could be observed over both hemispheres, it was greater over the contralateral hemisphere than over the ipsilateral hemisphere from $\sim 200 \mathrm{~ms}$ until the end of the epoch for the lower VF targets. This can be seen 


\section{Experiment 1 Alpha Topographic Plots (200 - 1200 ms)}

\section{a Upper VF}

\section{Left Target}
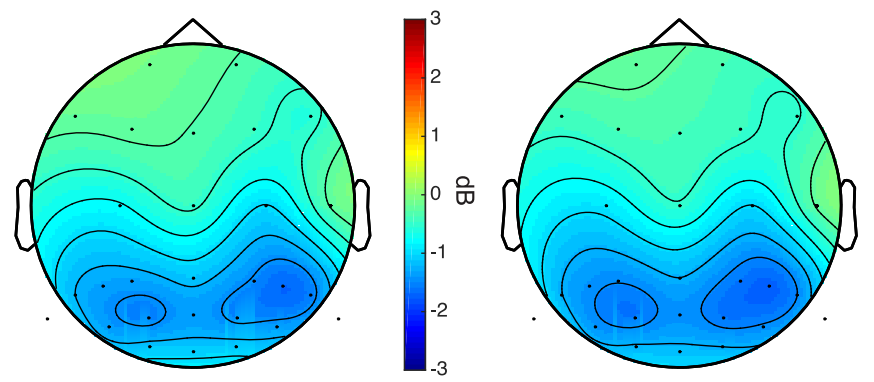

Right Target

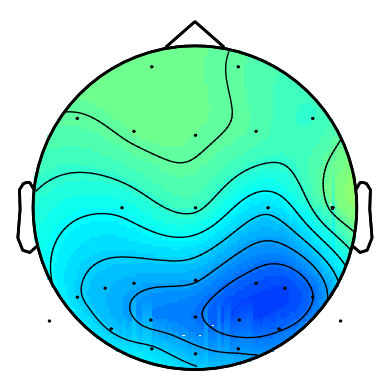

\section{b Lower VF}

\section{Left Target}

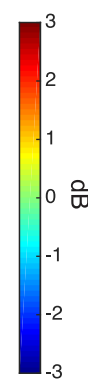

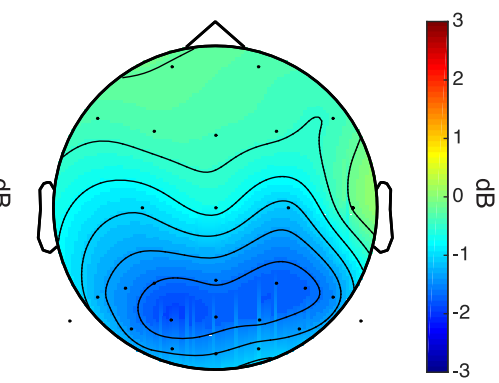

Right Target

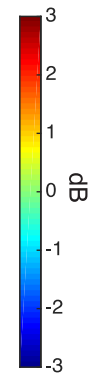

Contra - Ipsi Difference

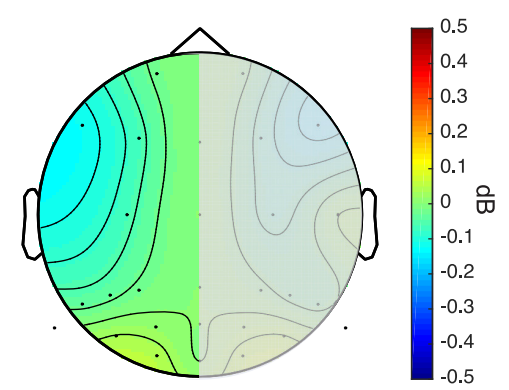

\section{Contra - Ipsi Difference}

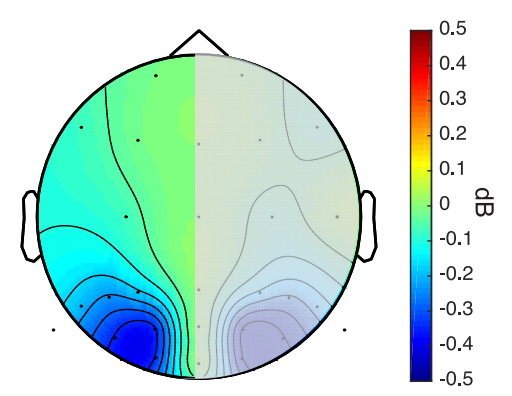

Figure 8. Topographic plots of induced alpha band ( $8-12 \mathrm{~Hz})$ activity during a longer time window ( $200-1200 \mathrm{~ms})$ for left and right targets and for the contralateral-minus-ipsilateral difference for upper VF $(\boldsymbol{a})$ and lower VF $(\boldsymbol{b})$ targets. A lateralization effect was observed for lower VF targets ( $\boldsymbol{b}$, right) but not for upper VF targets $(\boldsymbol{a}$, right).

most readily in the contralateral-minus-ipsilateral TF plots (Figs. $6 b$, right column), in the alpha-band time course waveforms (Fig. $6 c)$, and in the contralateral-minus-ipsilateral scalp maps (Figs. $7 b, 8 b$, right columns). No such contralaterality was visible for the upper VF targets. Note that the very early start time of the effect may reflect the loss of temporal information that necessarily occurs in a TF transform. Note also that, although the maximum effect was present at the same electrode sites as the N2pc (Fig. 5b), the alpha lateralization effect was more narrowly focused over posterior sites than was the N2pc.

To provide statistical support for the observed alpha lateralization effect, we performed an a priori statistical analysis of the mean power in the $8-12 \mathrm{~Hz}$ band using the same time window in which the N2pc component was present (156-276 ms poststimulus). To quantify the amount of contralaterality, we measured the difference in power between the contralateral and ipsilateral hemispheres (relative to the target location). We found that the contralaterality of the alpha power was significantly greater for the lower VF targets than for the upper VF targets $\left(t_{(20)}=2.42\right.$, $p=0.025)$.
Additional analyses of the other measurement windows indicated that the contralaterality was significantly greater for lower VF targets than for upper VF targets in all time windows (200$600 \mathrm{~ms}: t_{(20)}=3.99, p<0.001 ; 600-900 \mathrm{~ms}: t_{(20)}=2.77, p=$ $\left.0.011 ; 900-1200 \mathrm{~ms}: t_{(20)}=2.11, p=0.047\right)$.

One-sample $t$ tests showed that alpha-band contralaterality was significantly greater than zero for lower VF targets in all time windows $\left(156-276 \mathrm{~ms}: t_{(20)}=-2.28, p=0.033 ; 200-600 \mathrm{~ms}\right.$ : $t_{(20)}=-4.13, p<0.001 ; 600-900 \mathrm{~ms}: t_{(20)}=-3.45, p<0.01$; 900-1200 ms: $\left.t_{(20)}=-2.17, p=0.041\right)$. For upper VF targets, there were no statistically significant differences from zero in any of the measurement windows $\left(156-276 \mathrm{~ms}: t_{(20)}=1.53, p=\right.$ $0.14 ; 200-600 \mathrm{~ms}: t_{(20)}=-0.52, p=0.6 ; 600-900 \mathrm{~ms}: t_{(20)}=0.4$, $\left.p=0.69 ; 900-1200 \mathrm{~ms}: t_{(20)}=0.85, p=0.4\right)$.

Together, the results of this experiment show that visual search targets trigger a contralaterally larger suppression of alpha-band power. Therefore, lateralization of alpha-band activity with respect to the attended location is not limited to spatial precuing paradigms, suggesting that the underlying neural process may be used for active target processing as well as preparatory processing. This target- 


\section{Experiment 2 Behavioral Results}
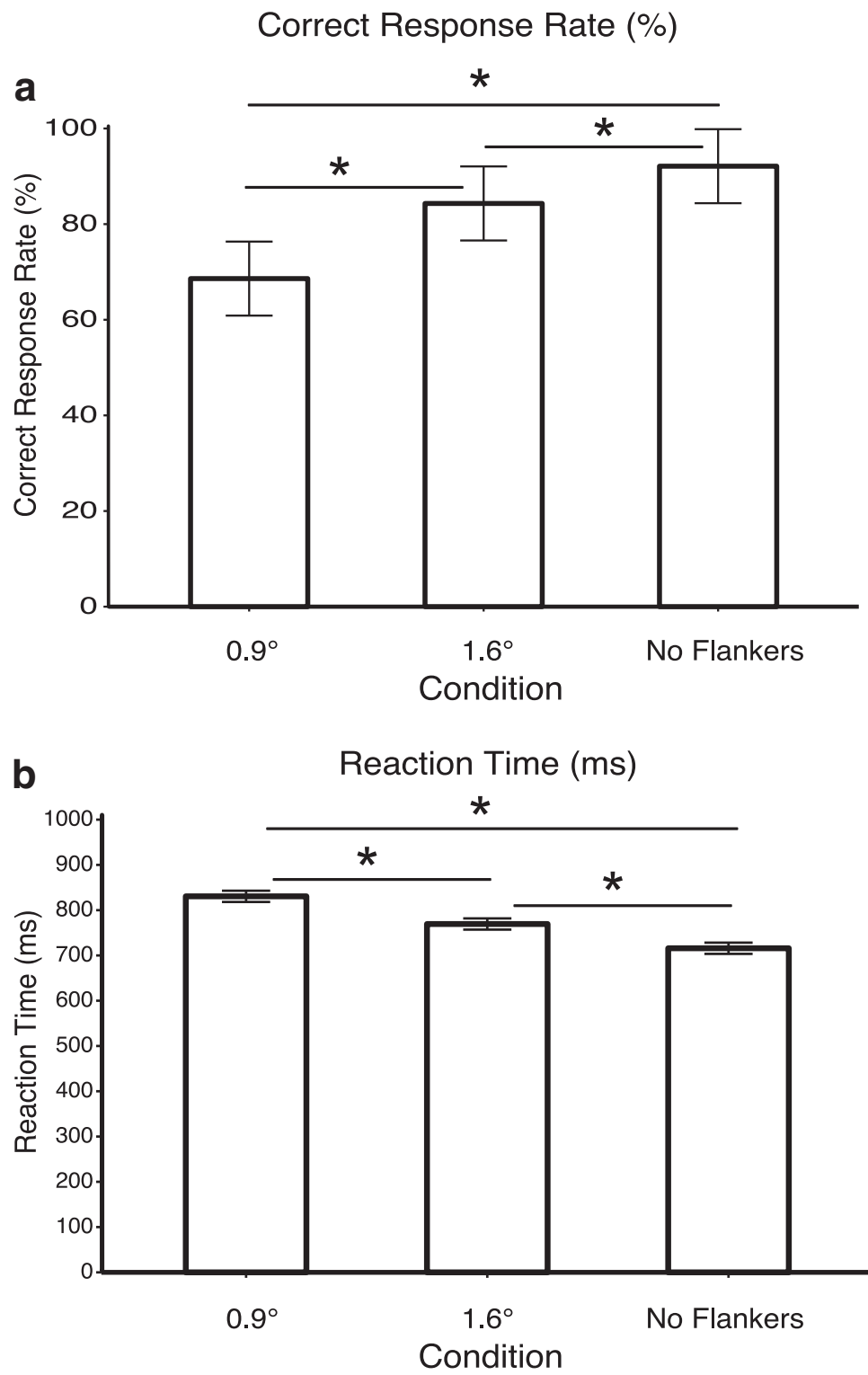

Figure 9. Mean correct response rate $(\boldsymbol{a})$ and RT $(\boldsymbol{b})$ for Experiment 2. This is a typical pattern showing decreased accuracy and longer RT for the most crowded conditions. Error bars indicate the within-subjects SEM. ${ }^{*} p<0.05$ for pairwise comparison.

more crowded. This resulted in a statistically significant main effect of distance in a one-way repeated-measures ANOVA $\left(F_{(2,40)}=143.6, p<0.001\right)$ and post hoc comparisons indicated significant differences among each of the three conditions (all $p<0.001$ ).

RTs showed the complementary pattern, becoming longer as the targetflanker distance decreased (Fig. 9b). The main effect of distance on RT was statistically significant $\left(F_{(2,40)}=32.3, p<0.001\right)$ and post hoc comparisons again indicated significant differences among each of the three conditions (all $p<0.001)$.

\section{Experiment 2 ERPs}

As shown in Figure 10, the voltage was more negative over the hemisphere contralateral to the target than the ipsilateral hemisphere during the N2pc measurement window (132-252 ms) for the $1.6^{\circ}$ flanker distance but not for the $0.9^{\circ}$ flanker distance or the no-flanker condition. This non-monotonic pattern of $\mathrm{N} 2 \mathrm{pc}$ amplitude exactly replicates our previous study of the effects of crowding on the N2pc component (Bacigalupo and Luck, 2015). As in Experiment 1, the N2pc was followed by two periods of sustained negative potential, one from $\sim 300-600$ ms and another from $\sim 700-1200 \mathrm{~ms}$. A repeated-measures ANOVA showed that differences in N2pc amplitude among the three trial types were statistically significant $\left(F_{(2,40)}=5.9, p=0.005\right)$ and post hoc Tukey comparisons indicated that N2pc amplitude was significantly greater for the $1.6^{\circ}$ distance than for both the $0.9^{\circ}$ distance and the no-flankers trials (all $p<$ 0.05). One-sample $t$ tests comparing the average amplitude to zero for each distance indicated that $\mathrm{N} 2 \mathrm{pc}$ amplitude was significantly different from zero only for the $1.6^{\circ}$ distance $\left(t_{(20)}=-3.83, p=\right.$ $0.001)$. Figure 11 shows that the N2pc at

elicited lateralized alpha suppression was similar to the N2pc component in two main ways. First, the time period of the alpha-band activity overlapped with the time period of the N2pc component. Second, both the N2pc and the contralateral alpha-band suppression were observed primarily for lower VF targets. However, the alpha suppression was much longer in duration than the N2pc component. The N2pc was quite brief, although it was followed by two later periods of negative potential, whereas the lateralized alpha-band suppression was present from $\sim 100 \mathrm{~ms}$ until the end of the epoch. Overall, these results suggest that the N2pc component and lateralized alpha-band suppression are closely related but separable processes. Experiment 2 was designed to determine whether these processes could be further separated.

\section{Experiment 2 behavior}

As shown in Figure $9 a$, behavioral accuracy was above $90 \%$ on no-flankers trials and decreased steeply as the stimuli became this distance had the typical occipitotemporal scalp distribution.

\section{Experiment 2 TF analysis}

As in Experiment 1, poststimulus alpha-band power decreased relative to the pre-stimulus period from $\sim 200-600 \mathrm{~ms}$ for all three flanker conditions at both ipsilateral and contralateral scalp sites (Fig. 12). The contralateral-minus-ipsilateral subtraction showed that the lateralization effect had an occipitotemporal scalp distribution (Figs. 13, 14). As in the lower VF target condition of Experiment 1, this effect was stronger over the contralateral hemisphere than over the ipsilateral hemisphere (relative to the target) and this contralaterality was greatest in the most crowded condition $\left(0.9^{\circ}\right)$. The differences among the three conditions were marginally significant for the 200-600 ms time window $\left(F_{(2,40)}=2.95, p=0.063\right)$ and did not approach significance for any of the other time windows $\left(132-252 \mathrm{~ms}: F_{(2,40)}=0.85\right.$, 
a No Flankers

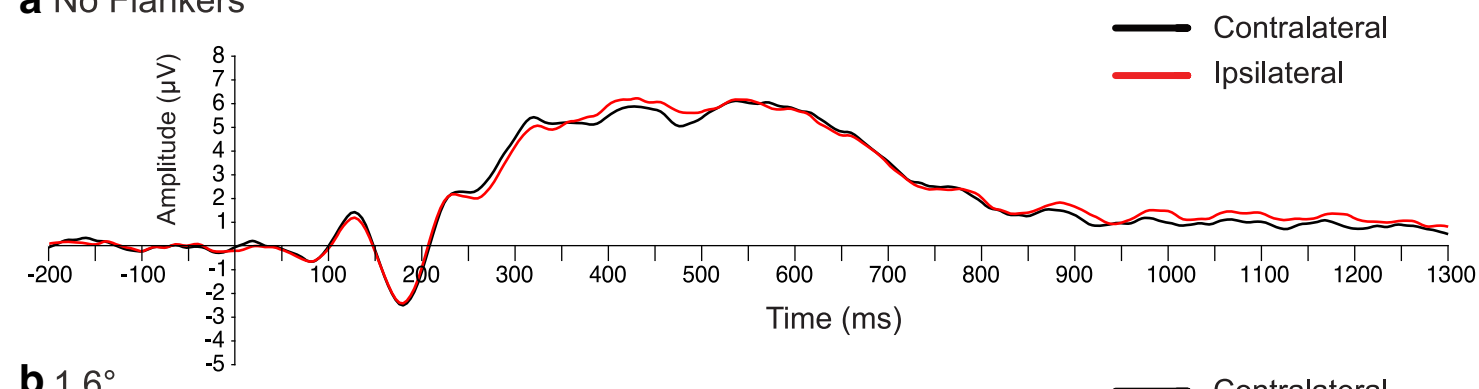

b $1.6^{\circ}$

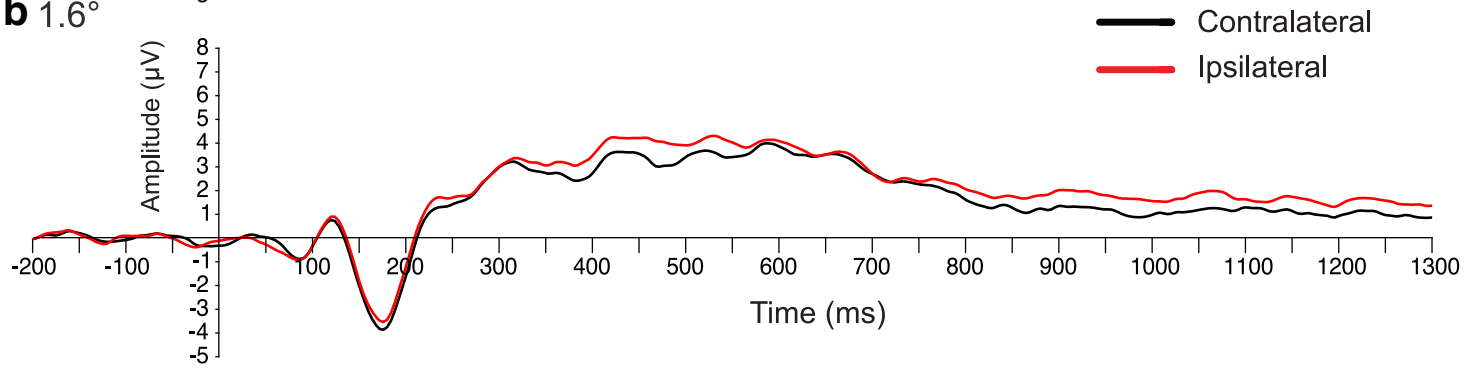

C $0.9^{\circ}$

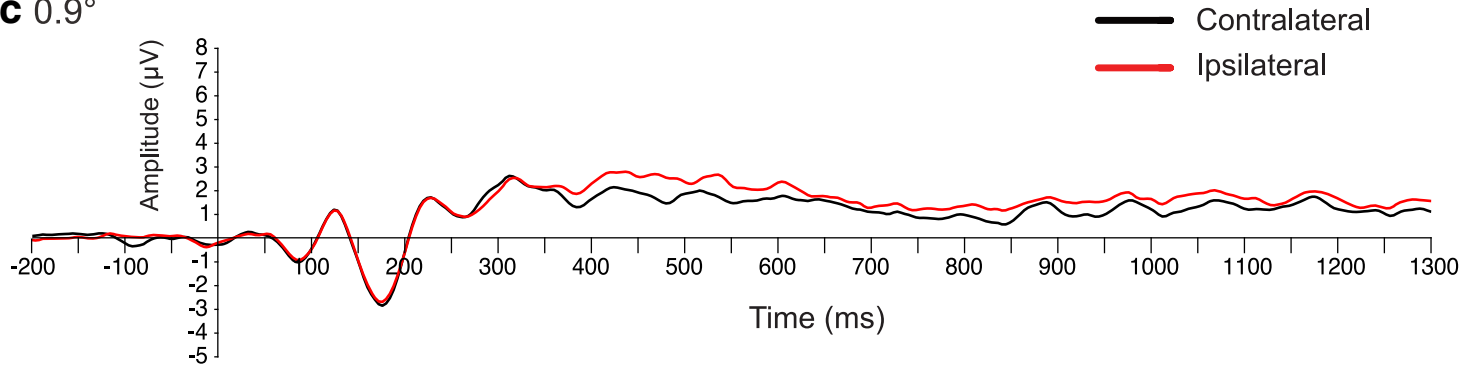

d Difference waves

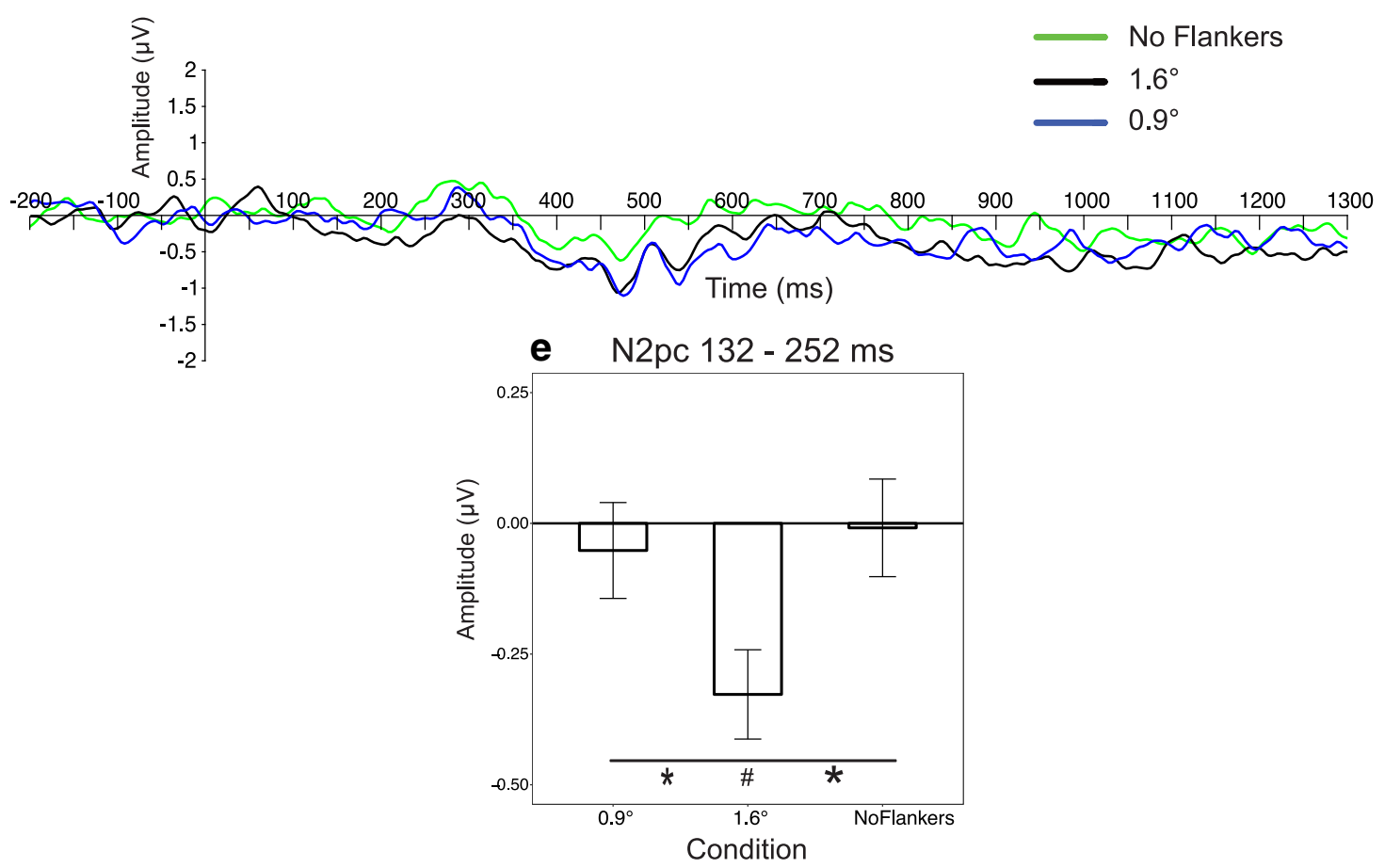

Figure 10. Experiment 2 grand-averaged ERPs. Contralateral and ipsilateral ERP waveforms are shown for the no-flankers condition (a), $1.6^{\circ} \mathrm{condition}(\boldsymbol{b})$, and $0.9^{\circ} \mathrm{condition}(\boldsymbol{c}) . \boldsymbol{d}, \mathrm{Contralateral-}$ minus-ipsilateral difference waves. $e$, Bar plots for the N2pc time window. Error bars indicate the within-subjects SEM. \#p $<0.05$ for one-sample $t$ test against zero. ${ }^{*} p<0.05$ for pairwise comparison. There was a significant N2pc effect only for the $1.6^{\circ}$ condition. 


\section{Experiment 2 N2pc Topographic Plots (132 - 252 ms)}

\section{a No Flankers}
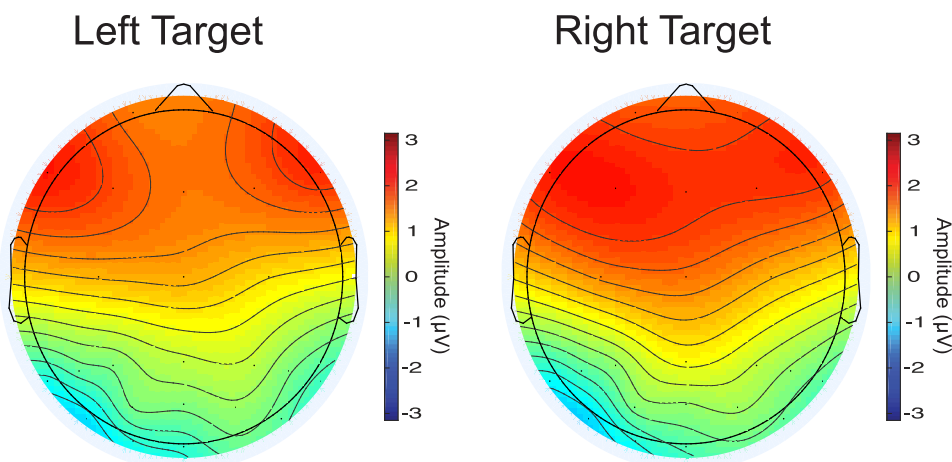

\section{Contra - Ipsi Difference}

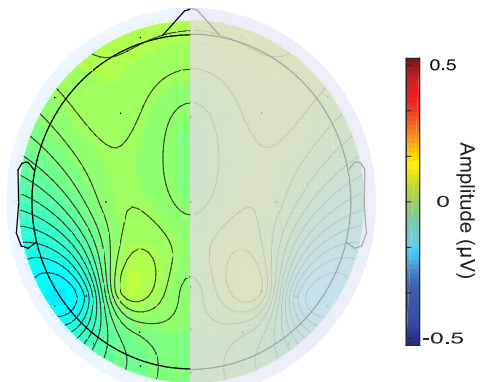

\section{Left Target}

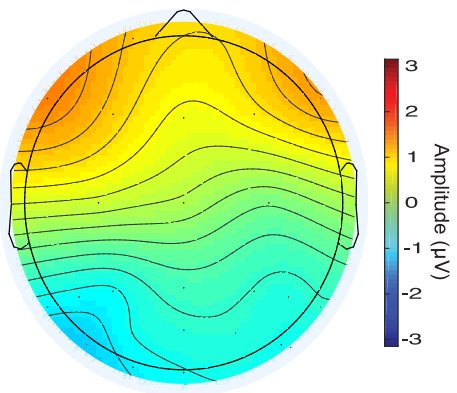

c $0.9^{\circ}$

\section{Left Target}

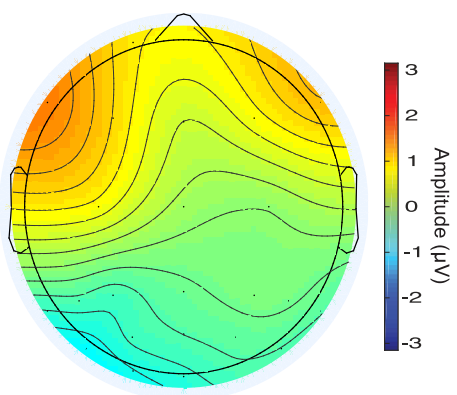

Right Target

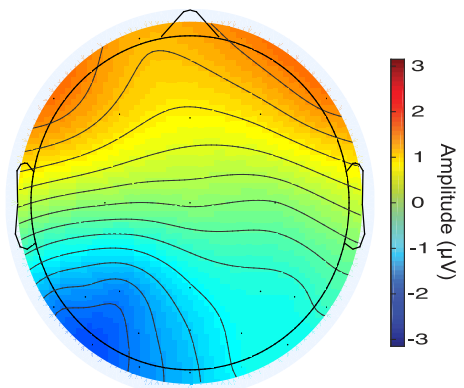

Contra - Ipsi Difference

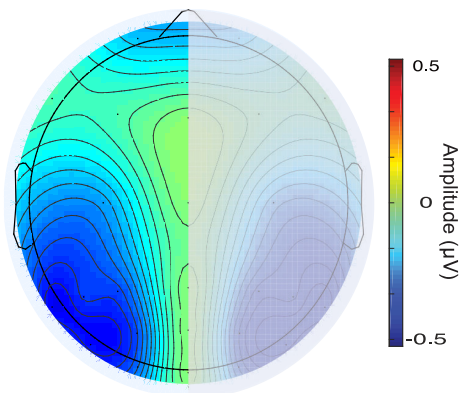

Right Target

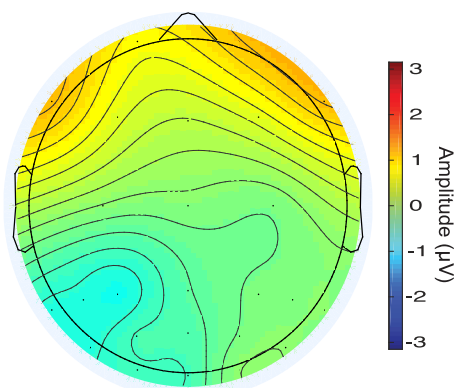

Contra - Ipsi Difference

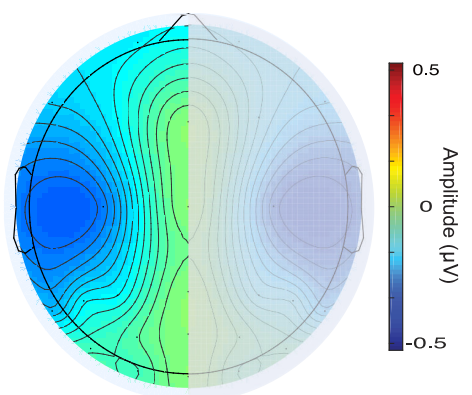

Figure 11. Topographic plots of the averaged ERP during the N2pc time window for left and right targets and for the contralateral-minus-ipsilateral difference for the no-flankers condition (a), $1.6^{\circ}$ condition $(\boldsymbol{b})$, and $0.9^{\circ}$ condition (c). The N2pc showed a typical occipitotemporal distribution for the $1.6^{\circ}$ condition.

$p=0.43 ; 600-900 \mathrm{~ms}: F_{(2,40)}=0.97, p=0.38$; and $900-1200 \mathrm{~ms}:$ $\left.F_{(2,40)}=1.02, p=0.36\right)$.

Further lateralization analyses comparing the contralateralminus-ipsilateral difference to zero in each condition indicated that the contralaterality was significant for the $0.9^{\circ}$ distance in all time windows for the $1.6^{\circ}$ distance during the 600-900 ms window and for the no-flankers condition during all time windows except for the earliest measurement window $\left(0.9^{\circ}=132-252 \mathrm{~ms}\right.$ : $t_{(20)}=-2.31, p=0.031 ; 200-600 \mathrm{~ms}: t_{(20)}=-4.78, p<0.001$;
600-900 ms: $t_{(20)}=-3.89, p<0.001 ; 900-1200 \mathrm{~ms}: t_{(20)}=$ $-2.51, p=0.021 ; 1.6^{\circ}=132-252 \mathrm{~ms}: t_{(20)}=-1.43, p=0.16$; $200-600 \mathrm{~ms}: t_{(20)}=-1.77, p=0.091 ; 600-900 \mathrm{~ms}: t_{(20)}=$ $-2.84, p=0.01 ; 900-1200 \mathrm{~ms}: t_{(20)}=-1.52, p=0.14$; NoFlankers $=132-252 \mathrm{~ms}: t_{(20)}=-1.75, p=0.094 ; 200-600 \mathrm{~ms}$ : $t_{(20)}=-3.69, p<0.01 ; 600-900 \mathrm{~ms}: t_{(20)}=-2.98, p<0.01$; 900-1200 ms: $\left.t_{(20)}=-2.65, p=0.015\right)$. Therefore, the effects of flanker distance for the target-elicited alpha-band lateralization were quite different from the effects observed for the N2pc component. 


\section{a No Flankers}
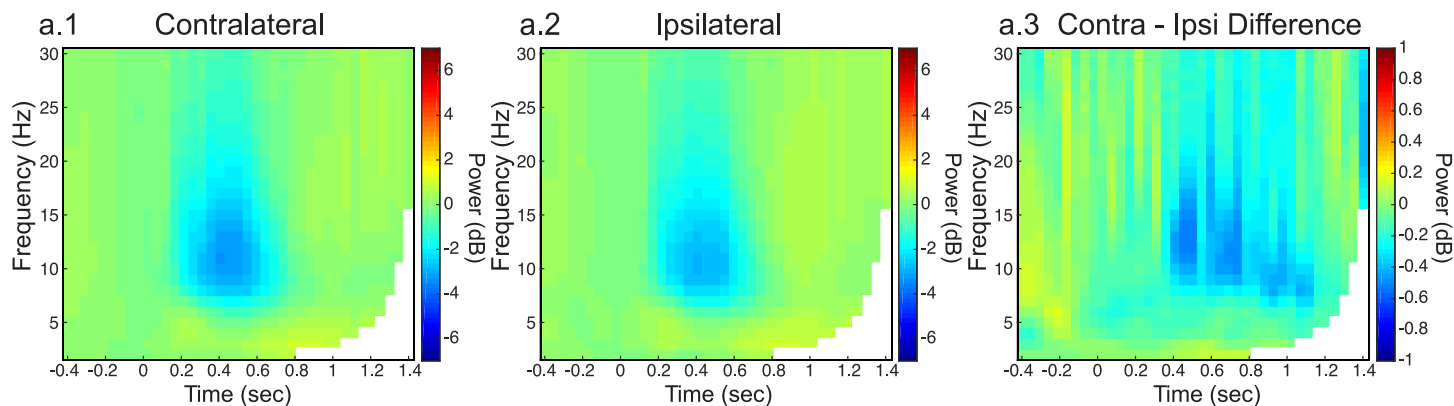

b $1.6^{\circ}$
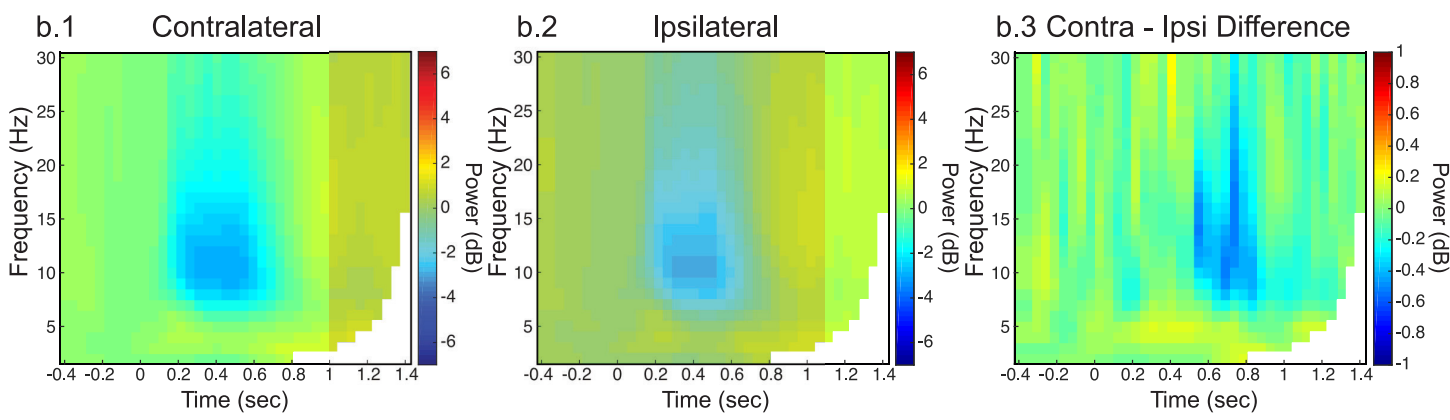

\section{C $0.9^{\circ}$}

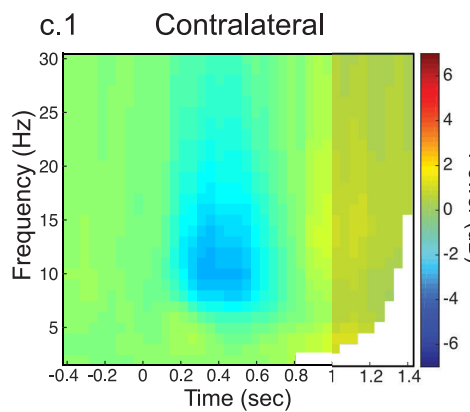

$$
\text { c. } 2
$$

Ipsilateral
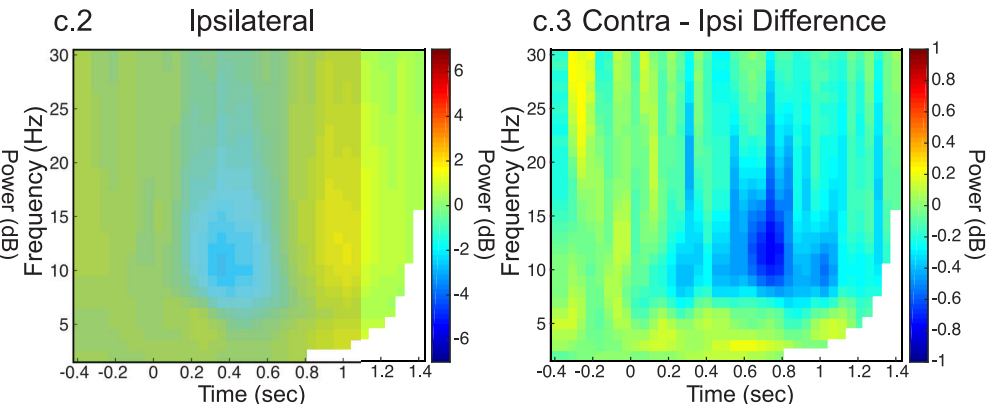

\section{d Alpha (8-12 Hz) Power (dB), Contra - Ipsi Difference}

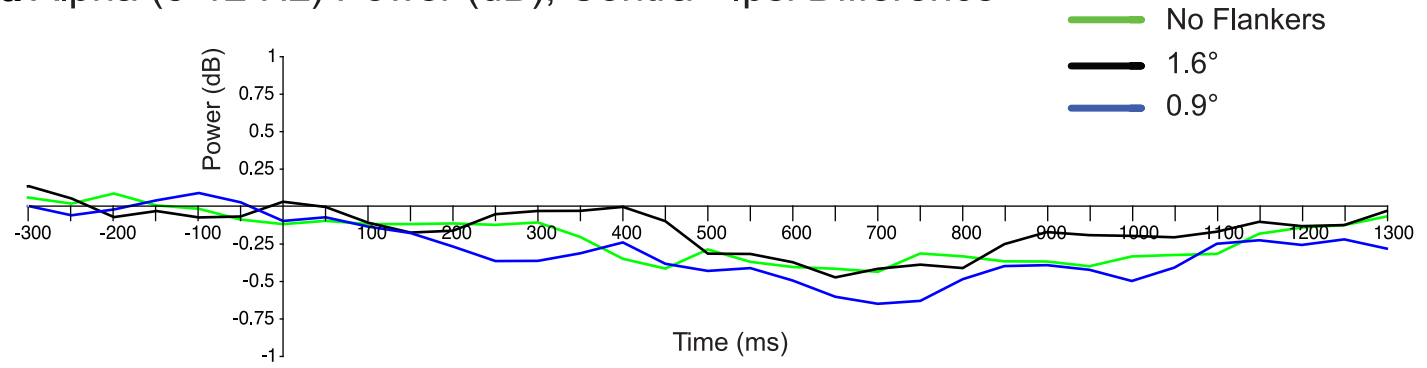

Figure 12. Grand-average TF plots from Experiment 2. Shown are contralateral, ipsilateral, and contralateral-minus-ipsilateral differences for the no-flankers condition (a), $1.6^{\circ}$ condition $(\boldsymbol{b})$, and $0.9^{\circ}$ conditions $(\boldsymbol{c})$. Target processing elicited greater alpha-band suppression over the contralateral hemisphere (right panels). The white region at the bottom right corner of the plots indicates values that are undefined given the epoch length and wavelet duration. $\boldsymbol{d}$, Time course of the contralateral-minus-ipsilateral difference in alpha-band power.

\section{Correlational analyses for Experiments 1 and 2}

We conducted a set of focused correlational analyses to determine whether the magnitude of the contralateral alpha-band suppression was associated with the magnitude of the N2pc component in each experiment. We also conducted a set of exploratory correlational analyses to examine associations between the alpha effect and the behavioral measures. Note, however, that our sample size $(N=21)$ was not sufficient to yield high levels of power for detecting correlations. With this sample size, the power to detect a moderate correlation of $r=0.4$ is only 0.45 (as indicated by $\mathrm{G}^{\star}$ Power; Faul et al., 2007). Moreover, because these analyses were largely exploratory, no correction for multiple comparisons was performed. Table 1 shows the correlations observed between the alpha-band effect (contralateral minus ipsilateral) in each of the time windows and the other variables (N2pc amplitude, RT, accuracy) for each condition in each of the two experiments. When considering the sign of the correlations, keep in mind that both the N2pc and the lateralized 


\section{Experiment 2 Alpha Topographic Plots (132 - $252 \mathrm{~ms})$}

\section{a No Flankers}

\section{Left Target}

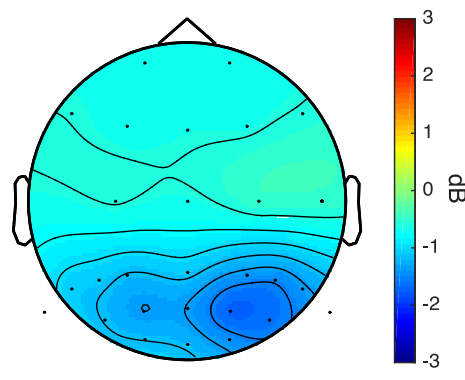

b $1.6^{\circ}$

\section{Left Target}

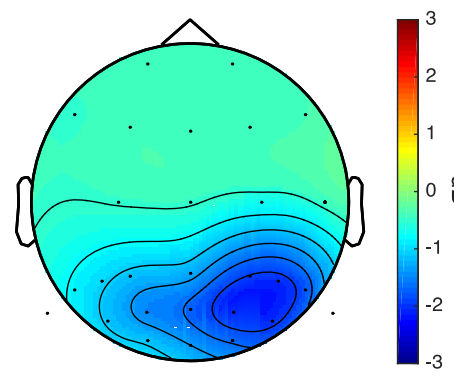

C $\quad 0.9^{\circ}$

Left Target

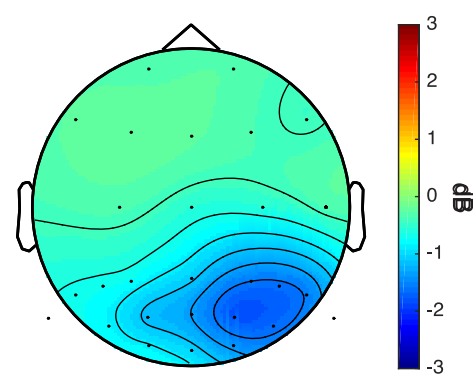

Right Target

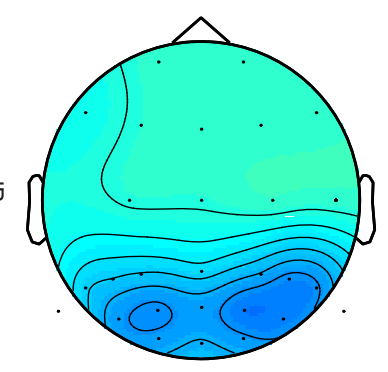

Contra - Ipsi Difference
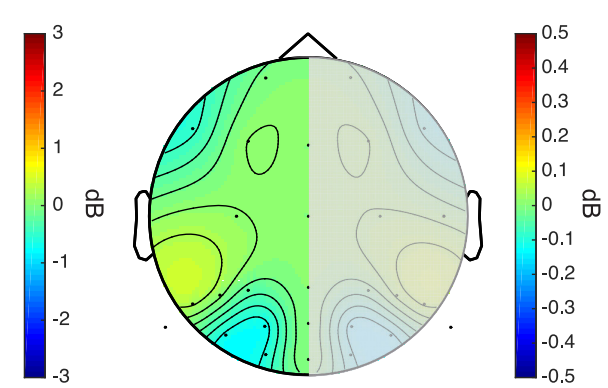

Contra - Ipsi Difference

Right Target

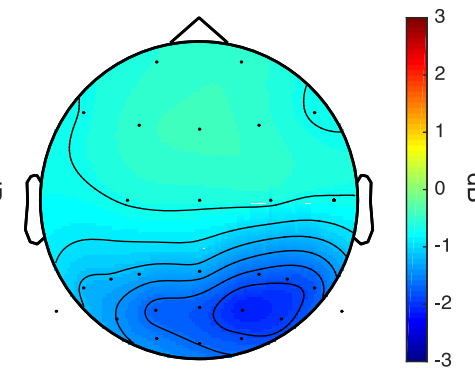

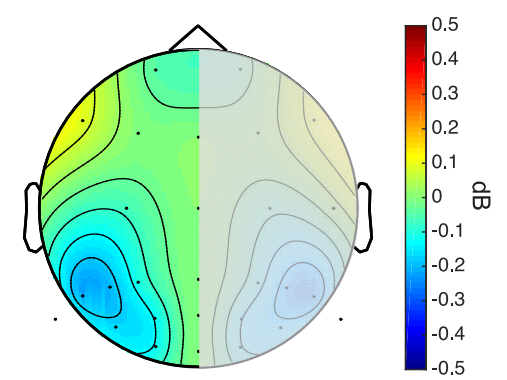

Contra - Ipsi Difference

Right Target

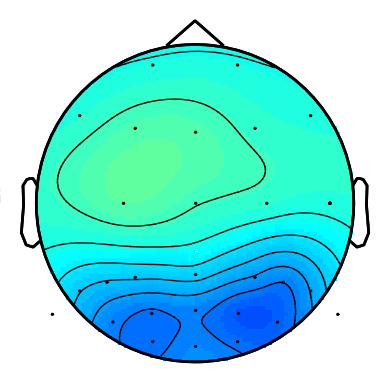

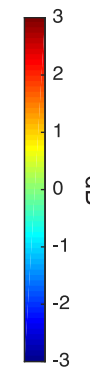

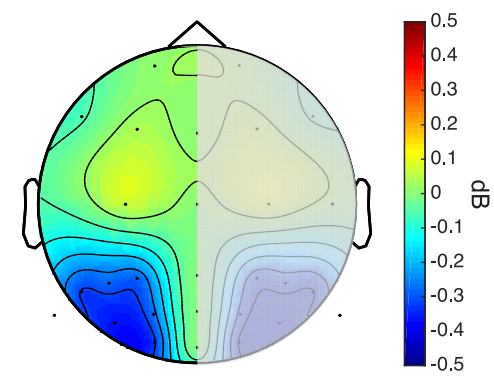

Figure 13. Topographic plots of induced alpha band $(8-12 \mathrm{~Hz})$ activity during the N2pc time window for left and right targets and for the contralateral-minus-ipsilateral difference for the no-flankers condition $(\boldsymbol{a}), 1.6^{\circ}$ condition $(\boldsymbol{b})$, and $0.9^{\circ}$ condition (c). Unlike the N2pc component, greater contralaterality was observed for the most crowded condition (c, right).

alpha suppression effects become more negative when they are larger.

When alpha-band activity and the N2pc component were both measured during the N2pc time window, the only significant correlation between them occurred in the most crowded condition of Experiment 2. The correlation was negative, indicating that the lateralized alpha-band suppression was greater in participants with smaller N2pc amplitudes in this condition. This is consistent with the possibility that the alpha-band activity is related to effort: participants who were unable to deploy the
$\mathrm{N} 2$ pc-related attentional mechanism in this condition may have found this condition to be more difficult, yielding a greater alphaband effect. However, a replication with a larger sample size would be necessary before strong conclusions could be drawn from this correlation.

When alpha-band activity was measured in the $200-600 \mathrm{~ms}$ interval, we found a significant negative correlation with N2pc amplitude for the upper VF stimuli in Experiment 1. The alphaband contralaterality in the 600-900 and 900-1200 ms time windows was also significantly positively correlated with RT for these 


\section{Experiment 2 Alpha Topographic Plots (200 - 1200 ms)}

\section{a No Flankers}

\section{Left Target}

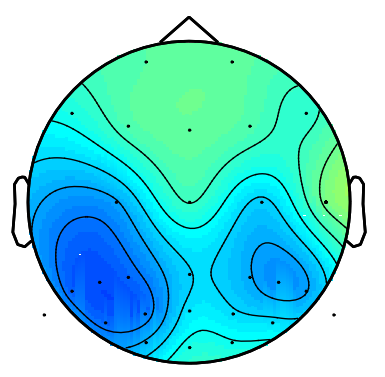

b $1.6^{\circ}$

\section{Left Target}

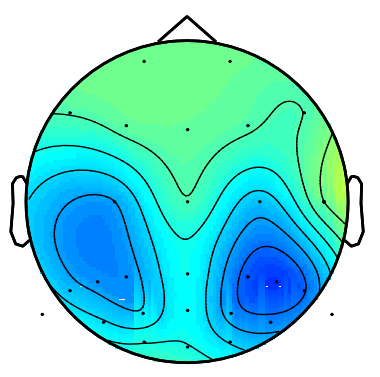

Right Target
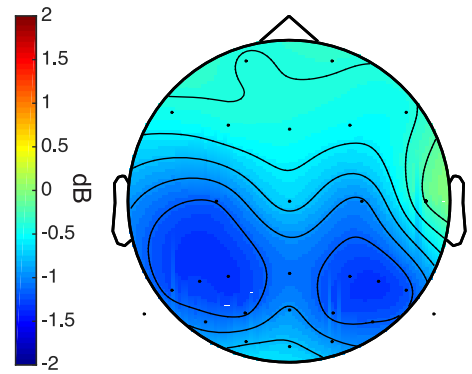

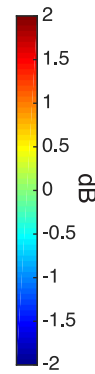

\section{Contra - Ipsi Difference}

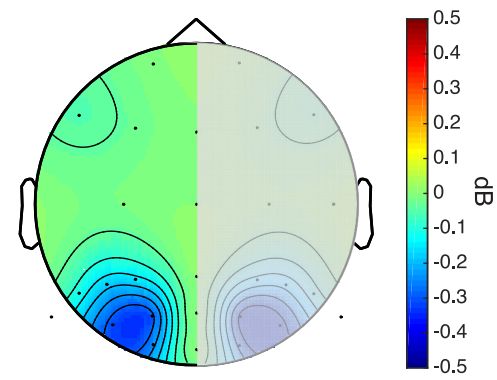

c $0.9^{\circ}$

Left Target

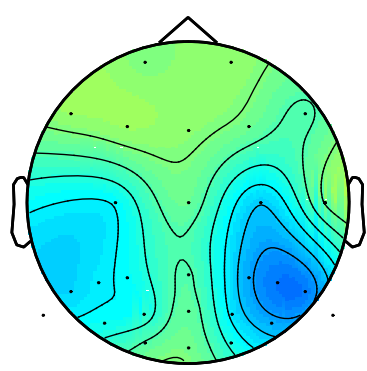

Right Target
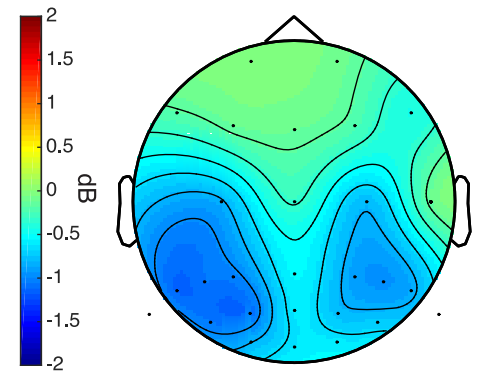

Contra - Ipsi Difference
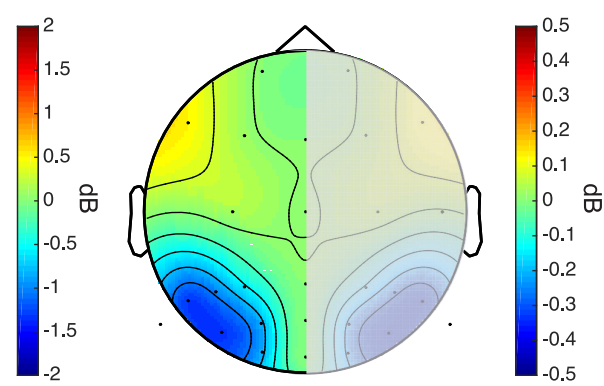
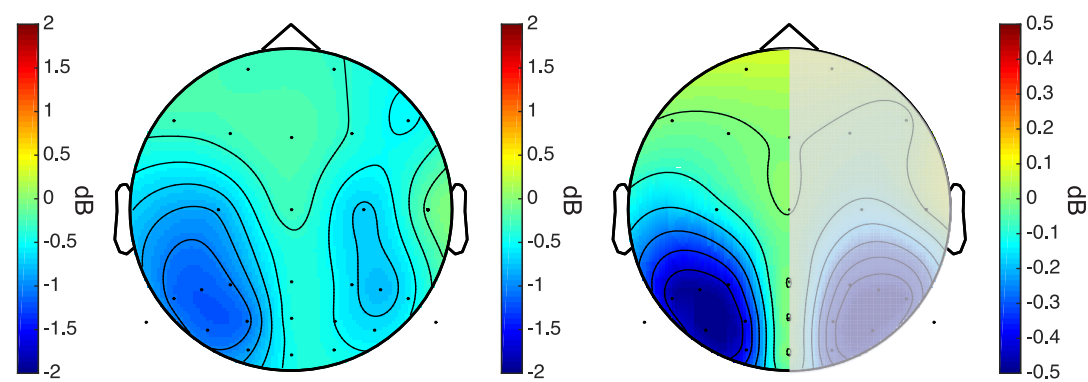

Figure 14. Topographic plots of induced alpha band $(8-12 \mathrm{~Hz})$ activity during a longer time window (200-1200 ms) for left and right targets and for the contralateral-minus-ipsilateral difference for the no-flankers condition (a), $1.6^{\circ}$ condition (b), and $0.9^{\circ}$ condition (c). Unlike the N2pc component, greater contralaterality was observed for the most crowded condition (c, right).

stimuli. However, given that neither the N2pc nor the alpha-band contralaterality was significantly different from zero for these stimuli, the meaning of these correlations is unclear. Significant positive correlations were also observed between alpha-band contralaterality in the 200-600 and 900-1200 ms time windows and behavioral accuracy for the no-flanker trials in Experiment 2. However, the correlations were not significant for the other trial types or for the other time windows. Again, it would be important to assess the replicability of these results using a larger sample size before attempting to draw any conclusions from these correlations.

\section{Discussion}

The present experiments demonstrate that visual search targets elicit a suppression of alpha-band EEG activity that is greater over the hemisphere contralateral to the target, indicating that alpha lateralization plays a role in target processing and does not solely 
Table 1. Correlations between alpha-band $(8-12 \mathrm{~Hz})$ power measured at different time windows with the N2pc and behavioral measures (RT and CR) for Experiment 1 and Experiment 2

\begin{tabular}{|c|c|c|c|c|}
\hline & Alpha $156-276 \mathrm{~ms}$ & Alpha $200-600 \mathrm{~ms}$ & Alpha $600-900 \mathrm{~ms}$ & Alpha $900-1200 \mathrm{~ms}$ \\
\hline \multicolumn{5}{|l|}{ Experiment 1} \\
\hline RT & $r=0.22(p=0.33)$ & $r=0.38(p=0.08)$ & $r=0.63(p=0.002)^{*}$ & $r=0.43(p=0.05)^{*}$ \\
\hline Correct response rate & $r=-0.26(p=0.24)$ & $r=-0.09(p=0.68)$ & $r=-0.18(p=0.42)$ & $r=-0.15(p=0.5)$ \\
\hline $\mathrm{N} 2 \mathrm{pc}$ & $r=0.18(p=0.43)$ & $r=-0.44(p=0.046)^{*}$ & $r=-0.16(p=0.48)$ & $r=-0.1(p=0.63)$ \\
\hline \multicolumn{5}{|l|}{ Lower VF target } \\
\hline $\mathrm{RT}$ & $r=-0.3(p=0.62)$ & $r=0.18(p=0.42)$ & $r=-0.1(p=0.66)$ & $r=-0.12(p=0.6)$ \\
\hline Correct response rate & $r=0.11(p=0.62)$ & $r=0.04(p=0.85)$ & $r=-0.11(p=0.63)$ & $r=-0.18(p=0.41)$ \\
\hline \multirow[t]{2}{*}{$\mathrm{N} 2 \mathrm{pc}$} & $r=0.16(p=0.47)$ & $r=0.39(p=0.074)$ & $r=0.16(p=0.47)$ & $r=0.11(p=0.64)$ \\
\hline & Alpha $132-252 \mathrm{~ms}$ & Alpha $200-600 \mathrm{~ms}$ & Alpha $600-900 \mathrm{~ms}$ & Alpha $900-1200 \mathrm{~ms}$ \\
\hline \multicolumn{5}{|l|}{ Experiment 2} \\
\hline \multicolumn{5}{|l|}{ No flankers } \\
\hline $\mathrm{RT}$ & $r=0.04(p=0.84)$ & $r=0.23(p=0.32)$ & $r=-0.03(p=0.87)$ & $r=-0.042(p=0.85)$ \\
\hline Correct response rate & $r=0.35(p=0.11)$ & $r=0.43(p=0.048)^{*}$ & $r=0.29(p=0.18)$ & $r=0.56(p=0.007)^{*}$ \\
\hline $\mathrm{N} 2 \mathrm{pc}$ & $r=0.23(p=0.31)$ & $r=-0.035(p=0.87)$ & $r=0.03(p=0.87)$ & $r=0.1(p=0.65)$ \\
\hline \multicolumn{5}{|c|}{ 1 } \\
\hline RT & $r=0.22(p=0.32)$ & $r=0.13(p=0.55)$ & $r=0.084(p=0.71)$ & $r=-0.16(p=0.49)$ \\
\hline Correct response rate & $r=0.01(p=0.96)$ & $r=0.05(p=0.82)$ & $r=0.23(p=0.29)$ & $r=0.22(p=0.33)$ \\
\hline $\mathrm{N} 2 \mathrm{pc}$ & $r=-0.019(p=0.93)$ & $r=0.13(p=0.56)$ & $r=0.14(p=0.52)$ & $r=0.06(p=0.79)$ \\
\hline \multicolumn{5}{|l|}{$0.9^{\circ}$} \\
\hline RT & $r=-0.28(p=0.21)$ & $r=-0.05(p=0.81)$ & $r=0.06(p=0.79)$ & $r=-0.23(p=0.3)$ \\
\hline Correct response rate & $r=0.13(p=0.56)$ & $r=0.24(p=0.28)$ & $r=0.25(p=0.27)$ & $r=0.2(p=0.36)$ \\
\hline $\mathrm{N} 2 \mathrm{pc}$ & $r=-0.56(p=0.008)^{*}$ & $r=-0.09(p=0.69)$ & $r=-0.14(p=0.54)$ & $r=-0.08(p=0.71)$ \\
\hline
\end{tabular}

${ }^{{ }^{*} p}<0.05$.

reflect preparatory processes. Furthermore, we found clear evidence that TELAS can be dissociated from the N2pc ERP component in terms of timing and the effects of crowding, indicating that these two lateralized scalp signals reflect separate mechanisms of attention that presumably play different functional roles.

Interestingly, Experiment 1 showed that both the N2pc and the target-elicited lateralized alpha suppression were largely absent for targets in the upper VF, whereas both signals were present for targets in the lower VF. This upper/lower difference has been observed previously for the N2pc component (Luck et al., 1997), but the reason for this effect is still not known. One possible explanation is neuroanatomical: the processing of the upper VF in ventral areas of the visual cortex may lead to dipoles that do not propagate well to the scalp. Another possibility is functional: previous research shows that visual attention operates somewhat differently in the upper and lower VFs (He et al., 1996; Kraft et al., 2011) and the mechanism of attention reflected by the N2pc may be used only when attention is directed to the lower VF. A third possibility is that the same processes are used for the upper and lower VFs, but the activity is lateralized only for the lower VF. The same possibilities also apply to the lack of target-elicited lateralized alpha suppression for upper VF targets. Note, however, that targets in both the upper and lower VFs elicited large reductions in alpha-band activity over both hemispheres; the only difference was that this effect was larger over the contralateral hemisphere for the lower VF targets but not for the upper VF targets. This provides tentative evidence against an anatomical explanation for the lack of a lateralized effect for upper VF targets, because these targets are clearly capable of producing large alpha suppression effects. The nature of the differences in attention for the upper and lower VFs will be an important topic for future research.

Differences between the upper and lower VFs were also observed for cue-related alpha lateralization in the seminal study of Worden et al. (2000), which involved precuing one of the four quadrants. Specifically, they reported that the scalp distribution of the lateralization was significantly more medial for the upper VF cues than for the lower VF cues. The lateralization effects also appeared to be stronger overall for the lower VF cues, consistent with the present target-related alpha lateralization effects, but unfortunately no statistical analysis of this apparent difference in magnitude was provided. It would be useful for future research to directly compare cue-elicited and target-elicited alpha lateralization effects to determine whether they reflect a common underlying mechanism.

Alpha lateralization effects have also been reported in relation to stimulus value. For example, Marshall et al. (2018) found that cue-related alpha lateralization was modulated by the presence of targets or distractors that had a positive or negative value. Therefore, alpha lateralization seems to be a ubiquitous mechanism of spatial attention, playing roles in preparation, value-related processing, and active target selection.

Although both the N2pc component and the lateralized alpha effects were limited to lower VF targets in Experiment 1, suggesting that they may be related, these effects had different time courses in both Experiments 1 and 2. Even taking into account the poorer temporal precision of the TF analyses, the alpha lateralization clearly lasted much longer than the N2pc (and the sustained contralateral negativity that followed the N2pc). Interestingly, the alpha effects lasted long after the behavioral response and well into the intertrial period, suggesting that they may reflect a relatively long-lasting modulation of processing.

As can be observed in the ERP waveforms in both Experiments 1 and 2 (Figs. 4 and 10, respectively), ERP lateralization effects were present long after the $\mathrm{N} 2 \mathrm{pc}$ and $\mathrm{P}_{\mathrm{D}}$ time windows. These effects consisted of contralateral negativities that occurred -300-600 ms and 700-1200 ms after target onset. The effect from 300-600 ms is likely the SPCN (Prime and Jolicoeur, 2010), which has been related to the maintenance of information online in working memory. This effect in Experiment 2 replicated the 
finding of our previous crowding study (Bacigalupo and Luck, 2015). The later effect, from 700-1200 ms, shares a similar timing with the alpha lateralization effect. Although this effect appeared to be larger for targets in the lower VF than in the upper VF, it was also clearly present for the upper VF targets (unlike the N2pc, SPCN, and alpha lateralization). Therefore, this late lateralized effect seems to be functionally independent from both the SPCN and the alpha lateralization and may be an interesting target for future research.

Experiment 2 also demonstrated a functional dissociation between the N2pc and the lateralized alpha suppression. Replicating previous findings (Bacigalupo and Luck, 2015), the N2pc amplitude was greater at the intermediate target-flanker distance $\left(1.6^{\circ}\right)$ compared with the no-flankers condition and the most crowded $\left(0.9^{\circ}\right)$ condition. This effect suggests that the mechanism of attention indexed by the N2pc operates mainly when multiple stimuli compete for access to the same receptive fields (Moran and Desimone, 1985; Luck et al., 1997; Hopf et al., 2006), but cannot operate effectively when the stimuli are too close to be resolved by attention (He et al., 1996; Intriligator and Cavanagh, 2001). The target-elicited lateralized alpha suppression did not show this non-monotonic pattern and instead exhibited a trend for greater lateralization as the difficulty of the task increased. If this increase in alpha lateralization with increases in task difficulty can be replicated, it would suggest that lateralized alpha suppression reflects effort rather than the actual selection of the target from among the distractors (which fails under highly crowded conditions).

Cue-elicited alpha lateralization effects have often been interpreted as an increase in alpha-band activity over the hemisphere contralateral to a to-be-ignored location rather than a decrease in alpha-band activity over the hemisphere contralateral to the cued location (Worden et al., 2000; Rihs et al., 2007; Jensen and Mazaheri, 2010; Mazaheri et al., 2014; Doesburg et al., 2016). In other words, the alpha-band activity may suppress the processing of stimuli at irrelevant locations rather than enhancing the processing of stimuli at relevant locations. However, the target-elicited lateralized alpha suppression observed in the present study seems more closely associated with target processing than with distractor suppression. The finding that the lateralized alpha effect varied according to the vertical position of the target in Experiment 1 would be difficult (although not impossible) to explain in terms of distractor suppression. In Experiment 2, the most potent distractors (in terms of effect on behavior) were the flankers immediately above and below the target, so the main items to be suppressed were on the same side as the target. Therefore, suppression of these items via increased alpha over the contralateral hemisphere would have produced increased rather than decreased alpha power over the hemisphere contralateral to the target. Therefore, target-elicited lateralized alpha suppression appears to mainly reflect active processing of the target rather than distractor suppression (Thut et al., 2006; Liu et al., 2016; Noonan et al., 2016). However, given the inverse relationship between alpha-band activity and cortical excitability (Klimesch, 2012), it seems plausible that alpha-band activity is related to both target enhancement and distractor suppression.

Although the target-elicited lateralized alpha suppression was dissociated from the N2pc component in terms of both timing and the effects of crowding, these two effects exhibited similar effects of the vertical position of the target. Therefore, although these two effects reflect dissociable mechanisms of attention, these processes appear to be closely related and may be generated in the same areas of visual cortex. Electrophysiological studies in monkeys have shown attention effects at the single-cell level in visual areas V2, V4, and inferotemporal cortex that are consistent with human N2pc patterns (Chelazzi et al., 1993; Luck et al., 1997) and Bollimunta et al. (2008) found single-unit attention effects related to alpha oscillations in these same areas (V2, V4, and IT). Therefore, the N2pc component and target-elicited lateralized alpha suppression may operate within the same neural substrates. It will be important for future research to disentangle the neural computations involved in generating these two separable measures of visuospatial attention.

\section{References}

Adrian ED, Matthews BH (1934) The Berger rhythm: potential changes from the occipital lobes in man. Brain 57:355-385. CrossRef Medline

Bacigalupo F, Luck SJ (2015) The allocation of attention and working memory in visual crowding. J Cogn Neurosci 27:1180-1193. CrossRef Medline

Berger H (1929) Uber das elektrenkephalogramm des menschen. Archiv fur Psychiatrie 87:527-570. CrossRef

Bollimunta A, Chen Y, Schroeder CE, Ding M (2008) Neuronal mechanisms of cortical alpha oscillations in awake-behaving macaques. J Neurosci 28:9976-9988. CrossRef Medline

Chelazzi L, Miller EK, Duncan J, Desimone R (1993) A neural basis for visual search in inferior temporal cortex. Nature 363:345-347. CrossRef Medline

Delorme A, Makeig S (2004) EEGLAB: an open source toolbox for analysis of single-trial EEG dynamics including independent component analysis. J Neurosci Methods 134:9-21. CrossRef Medline

Doesburg SM, Bedo N, Ward LM (2016) Top-down alpha oscillatory network interactions during visuospatial attention orienting. Neuroimage 132:512-519. CrossRef Medline

Eimer M (2015) EPS mid-career award 2014: the control of attention in visual search: cognitive and neural mechanisms. Q J Exp Psychol (Hove) 68:2437-2463. CrossRef Medline

Faul F, Erdfelder E, Lang AG, Buchner A (2007) G*Power 3: a flexible statistical power analysis program for the social, behavioral, and biomedical sciences. Behav Res Methods 39:175-191. Medline

Grandchamp R, Delorme A (2011) Single-trial normalization for eventrelated spectral decomposition reduces sensitivity to noisy trials. Front Psychol 2:236. CrossRef Medline

Gunter TC, Wijers AA, Jackson JL, Mulder G (1994) Visual spatial attention to stimuli presented on the vertical and horizontal meridian: an ERP study. Psychophysiology 31:140-153. CrossRef Medline

Hanslmayr S, Gross J, Klimesch W, Shapiro KL (2011) The role of alpha oscillations in temporal attention. Brain Res Rev 67:331-343. CrossRef Medline

He S, Cavanagh P, Intriligator J (1996) Attentional resolution and the locus of visual awareness. Nature 383:334-337. CrossRef Medline

Hopf JM, Luck SJ, Boelmans K, Schoenfeld MA, Boehler CN, Rieger J, Heinze HJ (2006) The neural site of attention matches the spatial scale of perception. J Neurosci 26:3532-3540. CrossRef Medline

Intriligator J, Cavanagh P (2001) The spatial resolution of visual attention. Cogn Psychol 43:171-216. CrossRef Medline

Jensen O, Mazaheri A (2010) Shaping functional architecture by oscillatory alpha activity: gating by inhibition. Front Hum Neurosci 4:186. CrossRef Medline

Klimesch W (2012) alpha-band oscillations, attention, and controlled access to stored information. Trends Cogn Sci 16:606-617. CrossRef Medline

Kraft A, Sommer WH, Schmidt S, Brandt SA (2011) Dynamic upper and lower visual field preferences within the human dorsal frontoparietal attention network. Hum Brain Mapp 32:1036-1049. CrossRef Medline

Lins OG, Picton TW, Berg P, Scherg M (1993) Ocular artifacts in EEG and event-related potentials. I: scalp topography. Brain Topogr 6:51-63. CrossRef Medline

Liu Y, Bengson J, Huang H, Mangun GR, Ding M (2016) Top-down modulation of neural activity in anticipatory visual attention: control mechanisms revealed by simultaneous EEG-fMRI. Cereb Cortex 26:517-529. CrossRef Medline

Lopez-Calderon J, Luck SJ (2014) ERPLAB: an open-source toolbox for the analysis of event-related potentials. Front Hum Neurosci 8:213. CrossRef Medline 
Luck S (2012) Electrophysiological correlates of the focusing of attention within complex visual scenes: N2pc and related ERP components. In: The Oxford Handbook of ERP Components (Luck S, Kappenman E, eds), pp 329-360. New York: Oxford UP.

Luck S (2014) An introduction to the event-related potential technique. Cambridge, MA: MIT.

Luck SJ, Gaspelin N (2017) How to get statistically significant effects in any ERP experiment (and why you shouldn't). Psychophysiology 54:146157. CrossRef Medline

Luck SJ, Hillyard SA (1994) Spatial filtering during visual search: evidence from human electrophysiology. J Exp Psychol Hum Percept Perform 20: 1000-1014. Medline

Luck SJ, Girelli M, McDermott MT, Ford MA (1997) Bridging the gap between monkey neurophysiology and human perception: an ambiguity resolution theory of visual selective attention. Cogn Psychol 33:64-87. CrossRef Medline

Maheux M, Jolicœur P (2017) Differential engagement of attention and visual working memory in the representation and evaluation of the number of relevant targets and their spatial relations: evidence from the N2pc and SPCN. Biol Psychol 125:28-35. CrossRef Medline

Marshall TR, den Boer S, Cools R, Jensen O, Fallon SJ, Zumer JM (2018) Occipital alpha and gamma oscillations support complementary mechanisms for processing stimulus value associations. J Cogn Neurosci 30: 119-129. CrossRef Medline

Mazaheri A, van Schouwenburg MR, Dimitrijevic A, Denys D, Cools R, Jensen O (2014) Region-specific modulations in oscillatory alpha activity serve to facilitate processing in the visual and auditory modalities. Neuroimage 87:356-362. CrossRef Medline

Moran J, Desimone R (1985) Selective attention gates visual processing in the extrastriate cortex. Science 229:782-784. CrossRef Medline

Noonan MP, Adamian N, Pike A, Printzlau F, Crittenden BM, Stokes MG (2016) Distinct mechanisms for distractor suppression and target facilitation. J Neurosci 36:1797-1807. CrossRef Medline

Oostenveld R, Fries P, Maris E, Schoffelen JM (2011) FieldTrip: open source software for advanced analysis of MEG, EEG, and invasive electrophysiological data. Comput Intell Neurosci 2011:156869. CrossRef Medline

Payne L, Guillory S, Sekuler R (2013) Attention-modulated alpha-band oscillations protect against intrusion of irrelevant information. J Cogn Neurosci 25:1463-1476. CrossRef Medline
Pollen DA, Trachtenberg MC (1972) Alpha rhythm and eye movements in eidetic imagery. Nature 237:109-112. CrossRef Medline

Previc F (1990) Functional specialization in the lower and upper visual fields in humans: its ecological origins and neurophysiological implications. Behav Brain Sci 13:519-575.

Previc FH, Blume JL (1993) Visual search asymmetries in three-dimensional space. Vision Res 33:2697-2704. Medline

Prime DJ, Jolicoeur P (2010) Mental rotation requires visual short-term memory: evidence from human electric cortical activity. J Cogn Neurosci 22:2437-2446. CrossRef Medline

R Development Core Team (2013) R: a language and environment for statistical computing. Vienna: R Foundation for Statistical Computing.

Ray WJ, Cole HW (1985) EEG alpha activity reflects attentional demands, and beta activity reflects emotional and cognitive processes. Science 228: 750-752. CrossRef Medline

Rihs TA, Michel CM, Thut G (2007) Mechanisms of selective inhibition in visual spatial attention are indexed by alpha-band EEG synchronization. Eur J Neurosci 25:603-610. CrossRef Medline

Sawaki R, Geng JJ, Luck SJ (2012) A common neural mechanism for preventing and terminating the allocation of attention. J Neurosci 32:1072510736. CrossRef Medline

Spaak E, de Lange FP, Jensen O (2014) Local entrainment of alpha oscillations by visual stimuli causes cyclic modulation of perception. J Neurosci 34:3536-3544. CrossRef Medline

Thaler L, Schütz AC, Goodale MA, Gegenfurtner KR (2013) What is the best fixation target? The effect of target shape on stability of fixational eye movements. Vision Res 76:31-42. CrossRef Medline

Thut G, Nietzel A, Brandt SA, Pascual-Leone A (2006) Alpha-band electroencephalographic activity over occipital cortex indexes visuospatial attention bias and predicts visual target detection. J Neurosci 26:9494-9502. CrossRef Medline

van Diepen RM, Miller LM, Mazaheri A, Geng JJ (2016) The role of alpha activity in spatial and feature-based attention. eNeuro 3: ENEURO.020416.2016. CrossRef Medline

Worden MS, Foxe JJ, Wang N, Simpson GV (2000) Anticipatory biasing of visuospatial attention indexed by retinotopically specific alpha-band electroencephalography increases over occipital cortex. J Neurosci 20:RC63. CrossRef Medline 